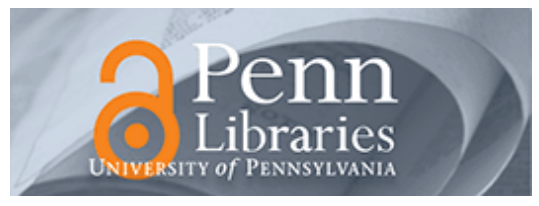

University of Pennsylvania

ScholarlyCommons

Management Papers

Wharton Faculty Research

7-2009

\title{
Social Connections and Incentives in the Workplace: Evidence From Personnel Data
}

Oriana Bandiera

Iwan Barankay

University of Pennsylvania

Imran Rasul

Follow this and additional works at: https://repository.upenn.edu/mgmt_papers

Part of the Business Administration, Management, and Operations Commons, and the Human Resources Management Commons

Recommended Citation

Bandiera, O., Barankay, I., \& Rasul, I. (2009). Social Connections and Incentives in the Workplace: Evidence From Personnel Data. Econometrica, 77 (4), 1047-1094. http://dx.doi.org/10.3982/ECTA6496

This paper is posted at ScholarlyCommons. https://repository.upenn.edu/mgmt_papers/47

For more information, please contact repository@pobox.upenn.edu. 


\title{
Social Connections and Incentives in the Workplace: Evidence From Personnel Data
}

\begin{abstract}
We present evidence on the effect of social connections between workers and managers on productivity in the workplace. To evaluate whether the existence of social connections is beneficial to the firm's overall performance, we explore how the effects of social connections vary with the strength of managerial incentives and worker's ability. To do so, we combine panel data on individual worker's productivity from personnel records with a natural field experiment in which we engineered an exogenous change in managerial incentives, from fixed wages to bonuses based on the average productivity of the workers managed. We find that when managers are paid fixed wages, they favor workers to whom they are socially connected irrespective of the worker's ability, but when they are paid performance bonuses, they target their effort toward high ability workers irrespective of whether they are socially connected to them or not. Although social connections increase the performance of connected workers, we find that favoring connected workers is detrimental for the firm's overall performance.
\end{abstract}

\section{Keywords}

favoritism, managerial incentives, natural field experiment

\section{Disciplines}

Business Administration, Management, and Operations | Human Resources Management 


\title{
Social Connections and Incentives in the Workplace: Evidence from Personnel Data*
}

\author{
Oriana Bandiera $^{\dagger} \quad$ Iwan Barankay $^{\ddagger} \quad$ Imran Rasul $^{\S}$ \\ May 2006
}

\begin{abstract}
We present evidence on the interplay between social connections, incentives, and productivity in the workplace. We address three questions - (i) whether and how social connections between workers and managers affect the performance of connected workers; (ii) whether and how they affect overall firm performance; and, (iii) whether the effect of social connections depends on the strength of managerial incentives. We identify these effects by combining panel data on individual worker's productivity from personnel records with a natural field experiment in which we engineered an exogenous change in managerial incentives from fixed wages to performance pay conditional on workers' average productivity. We find that when managers are paid fixed wages, they favor workers to whom they are socially connected, but when they are paid performance bonuses they do not. Although the favoritism generated by social connections increases the performance of connected workers, we show that favoring connected workers is not optimal for the firm's overall performance.
\end{abstract}

Keywords: favoritism, managerial incentives, natural field experiment.

JEL Classification: J33, M52, M54.

\footnotetext{
*Financial support from the ESRC is gratefully acknowledged. We have benefitted from comments from Simon Burgess, Arnaud Chevalier, Paul Grout, Costas Meghir, Antonio Merlo, Paul Oyer, Torsten Persson, Canice Prendergast, Kathryn Shaw, David Stromberg, John Van Reenen, Fabrizio Zilibotti, and seminar participants at Bristol, IFS, IIES, Surrey, SSE, Tinbergen, the CEPR Conference on Labor Market Relations in Bergen 2006, the LEaF 2006 conference at UCL, and the Utah Winter Finance Conference 2006. Brandon R.Halcott provided excellent research assistance. We thank all those involved in providing the data. This paper has been screened to ensure no confidential information is revealed. All errors remain our own.

${ }^{\dagger}$ Department of Economics, London School of Economics and Political Science, Houghton Street, London WC2A 2AE, United Kingdom; Tel: +44-207-955-7519; Fax: +44-207-955-6951; E-mail: o.bandiera@lse.ac.uk.

${ }^{\ddagger}$ Department of Economics, University of Essex, Wivenhoe Park, Colchester CO4 3SQ, United Kingdom. Tel:+44-1206-87-2729; Fax: +44-120-687-2724; E-mail: itbara@essex.ac.uk.

$\S$ Department of Economics, University College London, Drayton House, 30 Gordon Street, London WC1E 6BT, United Kingdom. Telephone: +44 (0)20 7679 5853; Fax: +44 (0)20 7916 2775; E-mail: i.rasul@ucl.ac.uk.
} 


\section{Introduction}

This paper explores the effects of social relationships between individuals within a firm, on individual and firm performance. The idea that human relations affect performance in the workplace has been long discussed in the sociology literature (Mayo 1933, Barnard 1938, Roethlisberger and Dickson 1939, and Roy 1952). Economists have joined this debate relatively recently, due both to the burgeoning theoretical literature on how social relations and social preferences matter for economic behavior, and the increasing availability of personnel data.

In the context of firms, much of the literature - theoretical and empirical - has studied the effects of social relations within one tier of the firm hierarchy, such as among managers, or among workers. ${ }^{1}$ However it is reasonable to expect that such social connections might also span across layers of the hierarchy, in particular between managers and workers, and that this is likely to have important consequences for individual and firm performance, the optimal design of compensation schemes, and the structure of organizations (Prendergast and Topel 1996). ${ }^{2}$

In general, social connections between managers and workers can help or harm firm performance. On the one hand, social connections may be beneficial to firm performance if they allow managers to provide non-monetary incentives to workers, or help reduce informational asymmetries within the firm. On the other hand, managers may display favoritism towards workers they are socially connected with, to the detriment of other workers and overall firm performance. ${ }^{3}$

To the extent that social connections affect firm performance, there may be important interactions between the compensation scheme for managers and the extent to which social connections are exploited. For example, as managerial compensation becomes more closely tied to firm performance, we would expect managers to utilize social connections to a greater extent if indeed, such connections are beneficial for firm performance.

This paper presents empirical evidence on the interplay between social connections, managerial incentives, and workers' performance. In particular we present evidence to identify - (i) whether social connections between workers and managers affect the performance of connected workers;

\footnotetext{
${ }^{1}$ Lazear (1989), Kandel and Lazear (1992), and Rotemberg (1994) develop models incorporating social concerns into the analysis of behavior within firms. While they emphasize that individuals have social concerns for others at the same tier of the firm hierarchy, their analysis is equally applicable across tiers of the hierarchy. Bewley (1999) offers extensive evidence from interviews with managers arguing that their concerns over fair outcomes for workers and the morale of employees are important determinants of their behavior.

${ }^{2} \mathrm{~A}$ related theoretical literature emphasizes the inefficiencies that arise from collusion between managers and workers (Tirole 1986, Kofman and Lawarrée 1993), influence activities, and other forms of rent seeking behavior by workers (Milgrom 1988, Milgrom and Roberts 1990).

${ }^{3}$ Both the positive and negative effects of social connections have been stressed in the organizational behavior and sociology literatures. Examples of such work includes that on the effect of manager-subordinate similarity on subjective outcomes such as performance evaluations, role ambiguity, and job satisfaction (Tsui and O'Reilly 1989, Thomas 1990, Wesolowski and Mossholder 1997), and on how social networks within the firm influence within firm promotions (Podolny and Baron 1997).
} 
(ii) whether the effect of social connections depends on the strength of managerial incentives; and, (iii) whether social connections between managers and some workers are detrimental to the firm's overall performance.

To address these questions we combine personnel data on workers' productivity with a natural field experiment in which we engineered an exogenous change in the managerial incentive scheme from fixed wages to performance pay based on the average productivity of managed workers.

The firm we study is a leading producer of soft fruit in the United Kingdom. We focus on the behavior of individuals at two tiers of the firm hierarchy - workers and managers. The main task of the workers is to pick fruit, whereas managers are responsible for logistics. Two key features of this setting are that workers are paid piece rates and that managerial effort is complementary to worker effort and can be targeted to individual workers. Taken together, these features imply that managers can affect a worker's productivity and hence his earnings.

Managers and workers are all hired for one picking season. They are university students from eight Eastern European countries and are thus of similar ages and backgrounds. In addition, they live on the farm site for the entire duration of their stay. Both features increase the likelihood of managers and workers forming strong social connections with each other.

To measure social connections we exploit three sources of similarity between managers and workers - whether they are of the same nationality, whether they live in close proximity to each other on the farm, and whether they arrived at a similar time on the farm. Our underlying assumption is that individuals are more likely to befriend others if they are of the same nationality, if they are neighbors, or if they share early experiences in a new workplace.

To identify the effect of social connections on connected workers and on the firm as a whole we exploit two sources of variation. First, the nature of production in our setting is such that the allocation of workers to managers changes daily. We exploit this quasi-random variation to identify the effect of social connections from the comparison of the performance of a given worker on days when he is socially connected to his manager, to days when he is not. Exploiting the within worker variation allows us to separate the effect of social connections from the effect of unobservable individual traits, for example ability, that make workers more likely to befriend managers and to have higher performance regardless of social connections.

Similarly, as we observe the same manager managing both workers she is socially connected to and workers she is not connected to, we are also able to control for time invariant sources of unobserved manager heterogeneity that affect the productivity of connected and unconnected workers alike, such as their management style or motivational skills. ${ }^{4}$

Second, we designed and implemented a field experiment to exogenously vary the strength of

\footnotetext{
${ }^{4}$ Our empirical strategy is informed by the evidence that individual 'styles' of managers affect firm performance over and above firm level characteristics themselves (Bertrand and Schoar 2003, Malmendier and Tate 2005).
} 
managerial incentives. In the experiment we changed the managerial compensation scheme from fixed wages to the same level of fixed wages plus a performance bonus that is increasing in the average productivity of the workers on the field that day. Workers were paid according to the same compensation scheme - piece rates - throughout.

The experiment allows us to identify whether and how the effect of social connections between the same managers and workers changes once managers are given performance pay and thus provides an ideal counterfactual to assess the effect of social connections on the overall firm's performance. To be precise, if the managers' behavior towards connected workers changes once their interests are more closely aligned with the firm's, their previous behavior under fixed wages could have not been maximizing the firm's average productivity.

Our main findings are as follows. First, when managers are paid fixed wages, the productivity of a given worker is significantly higher on days when he is assigned to managers he is socially connected to. The magnitudes of our estimates imply that the productivity of a given worker is $9.5 \%$ higher when he is socially connected to his manager, relative to when he is not, all else equal. As workers are paid piece rates, this translates into the same proportionate change in earnings. Hence when managers face low powered incentives, they favor workers they are socially connected to, and this has qualitatively and quantitatively significant effects on the individual performance of connected workers.

Second, when managers are paid performance bonuses that tie their pay to the average productivity of workers they manage, being socially connected to the manager has no effect on the worker's productivity. In short, when managers' interests are aligned with those of the firm and their pay is tied to average productivity, they change their behavior and do not favor workers they are socially connected to.

The fact that the difference-in-difference in worker productivity by social connectivity to his managers and managerial incentive scheme is positive indicates that, in this setting, favoring socially connected workers is not optimal for the firm's average productivity.

Third, we find the effect of social connections on the productivity of a given worker is stronger when fewer of his co-workers are also socially connected to the manager. This suggests that favors are a rival good in the sense that favoring one worker limits the ability of the manager to favor other workers also present on the field. This finding sheds light on the mechanism that links the existence of social connections across tiers of the firm hierarchy to overall firm performance. Indeed, if by favoring a connected worker the manager is unable to devote effort towards an unconnected worker who is of higher ability, the average firm productivity might fall overall.

Our paper contributes to the growing empirical evidence on the interplay between social networks and individual and firm performance. This literature has explored how the response of workers to incentives depends on their social connections with their co-workers at the same tier of 
the firm hierarchy (Bandiera et al 2005a), and how the demographic differences between managers and their subordinates affect the subordinates' rate of quits, dismissals and promotions (Giuliano et al 2005). Another branch of this literature has explored the effects of the CEO or managerial board of firms being socially connected to those outside of the firm such as local politicians and bureaucrats (Bertrand et al 2005, Kramarz and Thesmar 2005, Mian and Khwaja 2005). ${ }^{5} 6$

Methodologically, our paper provides a contribution in linking the benefits of natural field experiments (Harrison and List 2004) with the insights gained from 'insider econometric' analysis of firms (Ichniowski and Shaw 2003). Such an approach allows us to present evidence on whether social connections between managers and workers result in favoritism for a given set of managerial incentives, and how favoritism is affected by an exogenous change in managerial incentives. This in turn allows us to infer whether the existence of social connections is good or bad for firm performance, and shed light on the potentially optimal form of managerial compensation scheme.

The paper is organized as follows. Section 2 describes our context and experimental research design. Section 3 develops a theoretical framework to highlight the central forces at play when social connections can have potentially positive and negative effects on worker productivity. Section 4 describes the data, empirical method, and identifying assumptions. Section 5 presents the main results and robustness checks. Section 6 concludes with a discussion of the external validity of our findings. Proofs and further robustness checks are in the Appendix.

\section{The Context and Experimental Design}

\subsection{Context}

We analyze the behavior of managers and workers in the fruit picking division of a leading UK producer of soft fruit during the 2003 season. Workers and managers are hired from eight countries in Eastern Europe on seasonal contracts that last between three and six months. ${ }^{7}$ To be recruited, individuals must be full-time university students, and have at least one year remaining before graduation. Two features of the work environment increase the likelihood of individuals forming strong social connections to each other - (i) workers and managers are of similar ages and have

\footnotetext{
${ }^{5}$ In non firm settings, Garicano et al (2005) present evidence from soccer matches on how referees favor home teams in order to satisfy the crowds in the stadium. Laband and Piette (1994) show that journal editors use professional contacts to identify high impact papers. In that context favoritism thus reduces informational asymmetries and is efficiency enhancing in the market for scientific knowledge.

${ }^{6}$ Fehr and Fischbacher (2002) provide an overview of the laboratory evidence on social preferences in workplace environments. One branch of this stems from Akerlof (1982) and Akerlof and Yellen (1988) who view the labor relation as a partial gift exchange. A separate branch of this experimental literature presents evidence that workers care about their pay relative to other workers (Charness and Kuhn 2005).

${ }^{7}$ Their work permit allows them to work on other UK farms subject to the approval of the permit agency. Their outside option to employment at the farm is therefore to return home or to move to another farm during the season. Few workers are hired for consecutive seasons and workers are not typically hired from the local labor market.
} 
similar socioeconomic backgrounds; (ii) they live and work on the farm site for the entire duration of their stay, which on average is 100 days.

The workers' primary task is to pick fruit. They typically pick on two or three different fields each day. At the start of a field-day the manager allocates each worker to a row of fruit to be picked. Once a worker clears this row, the manager is responsible for reallocating the worker to another row within the field. This process continues until all fruit within the field is picked. As each worker picks on his own row, his productivity is independent of the efforts of other workers on the same field-day, so that there are no complementarities between workers arising from the production technology. Workers do not choose how many hours to work - all workers are present on the field-day for the number of hours it takes to pick all the available fruit. The only choice variable of workers is how much effort to exert into picking. ${ }^{8}$

Workers are paid a piece rate per kilogram of fruit picked. Each worker's pay is thus related to his productivity, which is an increasing function of his effort, the quantity of fruit available on the rows he is assigned, and of the managerial effort targeted towards him.

Managers are each assigned a group of around twenty workers, and their task is to organize the field logistics for this group. Managers on the same field focus on their assigned group of workers and work independently of each other. Field logistics include the allocation of workers to rows and organizing the movement of fruit from the field to the packaging plant. ${ }^{9}$

The key choice variables of each manager are the allocation of workers to rows, and the allocation of effort among her workers. Managers are responsible for allocating workers to rows at the start of the field-day, and for reallocating workers to new rows once they have finished picking the row they were originally assigned to. How the manager matches workers to rows is important because there is considerable variation in the quantity of fruit across rows within a field. Some of this is due to the natural variation in fruit quantity on different plants. This variation also stems from some rows being closer to pillars that support the plastic covering over the field. Rows close to pillars are harder to pick, air circulation is worse, and hence heat tends to accumulate. These factors reduce the marginal productivity of worker's effort in these rows, other things equal.

The manager chooses how to allocate her effort across workers along two dimensions. First, if several workers finish picking their rows at the same time the manager has to decide whom to reallocate to a new row first. Second, workers place the fruit they have picked into crates. Once these are full, managers have to ensure that new empty crates are provided to workers and that full crates are removed from the field and shipped to the packaging plant. If several workers

\footnotetext{
${ }^{8}$ Work is offered on a casual basis with no daily guarantee of employment. In practice, managers manage each day, and workers are engaged in picking tasks every other day. On other days workers are asked to perform non-picking tasks such as planting or weeding, or may be left unemployed for the day.

${ }^{9} \mathrm{~A}$ separate group of individuals, called field runners, are responsible for physically moving fruit from the field to the packaging plant. They do not themselves pick fruit nor do they manage workers.
} 
simultaneously fill their crates, the manager chooses whom to help first.

The effort costs to the manager are considerable because the workers she is responsible for are dispersed over a large area. The median field size in our sample is three hectares, and given there are typically three managers present, each has to cover an area of one hectare. To make sure she is aware of which workers need to be reallocated to new rows and which need their crates to be replaced, the manager needs to continuously walk around the field.

In this environment, managerial effort is complementary to worker's effort, namely, for a given effort level of the worker, his productivity is higher the more effort the manager targets towards him. For example, a manager can increase a worker's productivity by assigning him to more plentiful rows and removing his full crates quickly. ${ }^{10}$ The effect of managerial effort on worker productivity can be substantial. Assuming that workers pick at a constant speed, if the manager slacks for five minutes every hour and a worker is left to wait for a new crate for the same time, his productivity would be $5 / 60=8 \%$ lower.

Social connections between managers and workers can have two effects. First, if a manager is concerned about the pay of the workers she is socially connected to, she can allocate more of her effort towards them thus increasing their productivity and their earnings. Second, a manager might be better informed about the ability or skills of workers she is socially connected to or be able to exert stronger social pressure on them to work hard, both of which generate a difference in the allocation of managerial effort between connected and unconnected workers.

We now discuss the two important features of this work environment that allow us to assess whether social connections shape the managers' effort allocation choice and, as a consequence, workers' earnings, and how this depends on the compensation scheme in place for managers.

\subsection{Key Feature 1: Natural Variation}

The quantity of fruit available for picking varies across fields on any given day because fields vary in their physical size, and within a field over time because plants reach maturity at different times. The fruit is planted some years in advance, so the quantity of fruit to be picked is given. The order in which fields are picked is decided at the start of the season.

This natural variation implies that the demand and supply of picking labor varies across field-days. Hence the number of workers and managers on the field differs across field-days. While farm management ensures the ratio of managers to workers is held constant, this natural variation implies the same worker can be supervised by different managers on different field-days. Importantly for our study, a worker can be supervised by a manager he is socially connected to

\footnotetext{
${ }^{10}$ Managerial and worker effort are not substitutes because managers themselves never pick fruit. Over the season, individuals are not observed moving across tiers of the hierarchy from picking tasks to managerial tasks or vice versa.
} 
on some field-days, and by another manager that he is not socially connected to on others.

Neither managers nor workers choose which field to work on or whom they work with. Rather, they are allocated to fields by a higher-tier employee, whom we refer to as the chief operating officer (COO), and is a permanent employee of the farm. The allocation of workers and managers to fields is made on the basis of the quantity of fruit to be picked on different fields that day, and the demand for non-picking tasks such as planting and weeding.

In Section 4 we present the underlying assumptions that allow us to exploit this quasi-random source of variation to identify the effects of social connections in the workplace. In the Appendix we present evidence directly related to these identifying assumptions.

\subsection{Key Feature 2: The Experimental Research Design}

We designed and implemented a field experiment in which we exogenously changed the compensation scheme of managers. At the start of the 2003 season, managers were paid a fixed wage. Midway through the 2003 season, we added a performance bonus to the same level of fixed wages. The experiment left the compensation scheme of the workers unchanged - workers were paid piece rates throughout the 2003 season. $^{11}$

The bonus payment was awarded on field $f$ and day $t$ if the workers average productivity on the field-day, $\bar{Y}_{f t}$, exceeded an exogenously fixed threshold, $Y^{*}{ }^{12}$ Conditional on reaching the threshold, the total monetary value of the bonus payment available to the managers, $B\left(\bar{Y}_{f t}\right)$ increases at an increasing rate in the average field-day productivity. ${ }^{13}$ Each manager then obtains an equal share of the bonus payment generated on the field-day. If there are $M_{f t}$ managers present, each obtains a payment of $\frac{1}{M_{f t}} B\left(\bar{Y}_{f t}\right)$.

\footnotetext{
${ }^{11}$ The change in incentives affected both the managers and the COO. The change was announced to the COO and managers a week in advance of the actual change. During this week, we spent time going through numerical examples with management to make sure they understood how the performance bonus would be calculated. Workers were not informed of the change in managerial compensation, but given that managers and workers live on the farm, they are likely to have understood the change over time.

${ }^{12}$ To avoid multi-tasking concerns (Holmstrom and Milgrom 1991), the performance bonus was not awarded if the quality of fruit picking declined. Quality is measured in two ways. First is simply the quantity of damaged fruit. Second, fruit has to be classified as either suitable for market or supermarket. This classification is largely based on the size of each fruit. If the percentage of damaged or misclassified fruit rose by more than $2 \%$ of a pre-established norm, then the performance bonus was not awarded that field-day.

${ }^{13}$ The bonus payment schedule is piecewise linear;

$$
B\left(\bar{Y}_{f t}\right)=\left\{\begin{array}{cll}
0 & \text { if } & Y^{*}>\bar{Y}_{f t} \\
a_{1}+b_{1} \bar{Y}_{f t} & \text { if } & Y^{*}+c_{1}>\bar{Y}_{f t} \geq Y^{*} \\
a_{2}+b_{2} \bar{Y}_{f t} & \text { if } & Y^{*}+c_{2}>\bar{Y}_{f t} \geq Y^{*}+c_{1} \\
a_{3}+b_{3} \bar{Y}_{f t} & \text { if } & \bar{Y}_{f t}>Y^{*}+c_{2}
\end{array}\right.
$$

where $a_{i}, b_{i}$ and $c_{i}$ are constants such that $a_{3}<a_{2}<a_{1}, b_{3}>b_{2}>b_{1}, c_{2}>c_{1}$. This reflects the fact that the marginal cost of supplying managerial effort is increasing. The parameters $a_{i}, b_{i}$, and $c_{i}$ are set such that $B\left(\bar{Y}_{f t}\right)$ is a continuous and convex function. The values of $a_{i}, b_{i}, c_{i}$, and $Y^{*}$ cannot be provided due to confidentiality.
} 
The fraction of field-days on which the bonus was earned varies from 20 to $50 \%$ across managers. The ex post monetary value of the performance bonus to managers is substantial. Averaged across all field-days actually worked under the bonus, managerial hourly earnings increased by $7 \%$. Conditional on obtaining the bonus, managerial hourly earnings increased by $25 \%$. The true expected hourly earnings increase to managers of the performance bonus scheme lies between these two bounds. ${ }^{14}$

The managers were unaware they were taking part in an experiment and that the data would be used for scientific research. As such, our experiment is a natural field experiment according to the taxonomy of Harrison and List (2004). The managers were however aware that productivity data were recorded and kept by the farm owner, and that the data would be analyzed to improve the firms' overall efficiency.

To identify whether managers allocate more effort to workers they are socially connected to, we compare the productivity of the same worker on field-days in which he is socially connected to his manager, to his productivity on field-days in which he is not socially connected to his manager. We exploit the exogenous variation in managerial incentives our research design provides to identify whether the effects of social connections depend on the managerial incentive scheme in place. The comparison also allows us to establish whether social connections are beneficial or detrimental to the firm's overall performance.

\section{Theoretical Framework}

We develop a stylized model of the behavior of managers and workers to analyze the effect of social connections across tiers of the firm's hierarchy, on the productivity of connected workers and the firm's overall performance. Our aim is to determine whether social connections can affect worker and firm performance in equilibrium, and how the effect of social connections depends on the strength of managerial incentives. The model is tailored to fit our particular context and experimental design and to highlight the main economic forces at play.

\subsection{Technology, Preferences, and Incentives}

For parsimony and without loss of generality, we assume production requires one manager and two workers in any given field. Workers pick fruit, and the manager organizes logistics for each worker. The output of worker $i$ is given by $y_{i}=\left(1+k_{i} m_{i}\right) e_{i}$, where $e_{i}$ is his effort, $m_{i}$ is the managerial

\footnotetext{
${ }^{14}$ Given that - (i) managers are from Eastern Europe; (ii) their base pay is $20 \%$ higher than the UK minimum wage; (iii) most individuals save earnings to spend later in their home country, these increases in hourly earnings translate into large increases in real income. As of January 2003, gross monthly earnings at the UK minimum wage $(\in 1105)$ are 5 times as high as at the minimum wage in Poland $(\in 201)$, where $40 \%$ of managers come from, and almost 20 times higher than in Bulgaria $(\in 56)$, where $30 \%$ of managers come from.
} 
effort targeted towards him, and $k_{i}>0$ is a measure of the strength of the complementarity between the manager's and worker's efforts. To make matters concrete, the managerial effort directed towards a worker can be thought of as the effort devoted to ensuring worker $i$ is allocated a new row of fruit as soon as he is done picking the current one.

The productivity of worker $i$, measured as the kilograms of fruit picked per hour, is defined as $y_{i} / h$, where $h$ is the number of hours worked on the field. This is the same for all workers in the field and so we make the simplifying assumption that $h=1$. This implies that in our framework output and productivity coincide.

Workers are paid a piece rate $\beta>0$ per kilogram fruit picked, and is taken as given by workers. This is also the same for all workers in the field and so we make the simplifying assumption that $\beta=1$. The total pay of worker $i$ is therefore $p_{i}^{W}=y_{i}$. Worker $i$ has a disutility of effort of $\frac{1}{2} \theta_{i} e_{i}^{2}$, where $\theta_{i}$ captures the heterogeneity across workers, and is interpreted as the inverse of the worker's innate ability. The utility of a worker is assumed to be linear and additively separable between pay, $y_{i}$, and effort, $-\frac{1}{2} \theta_{i} e_{i}^{2}$.

The manager's compensation schedule is $p^{M}=f+b \bar{Y}$, where $f$ is a fixed wage and $\bar{Y}=\frac{1}{2} \sum_{i} y_{i}$ is the average productivity of her subordinates. The parameter $b \geq 0$ captures the strength of managerial incentives, namely the variable component of managerial pay which is linearly related to average worker productivity. We assume the manager has one unit of effort available and chooses how to allocate it between the workers such that $\sum_{i} m_{i}=1$. This assumption allows us to highlight how the manager's allocation of effort across workers changes with her incentive scheme, while holding constant her overall effort. Allowing the manager to also choose her level of effort leaves the qualitative results unchanged.

\section{Social Connections}

Social connections can affect, in reduced form, both the preferences of the agents, and the production technology. To capture the former channel we follow Prendergast and Topel (1996), and model social connections by assuming the manager's utility depends on her pay and the pay of her subordinates, that is,

$$
u^{M}=p^{M}+\sum_{i} \sigma_{i} p_{i}^{W}
$$

where $\sigma_{i}$ measures the social connection between the manager and worker $i$. We assume that $\sigma_{i}=\sigma>0$ if worker $i$ is connected to the manager while $\sigma_{i}=0$ if he is not. ${ }^{15}$ The preferences in (1) can be seen to represent "altruism" but also as the reduced form of a model in which the manager cares about the connected workers' earnings because she receives kickbacks from them.

\footnotetext{
${ }^{15}$ We focus on whether managers and workers are socially connected or not, rather than on the strength of the social connection. What matters for the analysis is that managers may be connected to a greater extent to some workers than others. We also focus on the case in which $\sigma \geq 0$. A negative weight could be interpreted as the manger being spiteful towards the worker.
} 
To the extent that social connections ameliorate the moral hazard problem between the manager and the workers, they affect workers' productivity directly. This would also be the case if social connections foster cooperation or improve communication between managers and workers in the workplace. To capture this second channel we assume the strength of the complementarity between managerial and worker effort depends on their social connections, that is given worker $i$ 's productivity, $y_{i}=\left(1+k_{i} m_{i}\right) e_{i}$, we assume $k_{i}=k>1$ if worker $i$ is connected to the manager, namely if $\sigma_{i}=\sigma$, while $k_{i}=1$ if he is not.

\subsection{The Workers' Effort Choice}

Each worker chooses his effort taking managerial effort as given. Note that workers' effort affects average productivity and hence the manager's pay when $b>0$, which raises the issue of whether the workers' utility should depend on the manager's as well as their pay when workers and the manager are socially connected. In practice, however, each manager supervises twenty workers. Hence each worker's contribution to average productivity and therefore his effect on the manager's pay is trivial. Given that workers' utility is linear and additively separable in their own pay, $y_{i}$, and cost of effort, $-\frac{1}{2} \theta_{i} e_{i}^{2}$, worker $i$ 's optimal effort choice then is,

$$
e_{i}^{*}=\frac{\left(1+k_{i} m_{i}\right)}{\theta_{i}} .
$$

Workers optimally exert more effort when the managerial effort targeted towards them increases because managerial and worker effort are complementary in the production technology. In addition, effort is decreasing in $\theta_{i}$, so high ability workers optimally exert more effort than low ability workers, other things equal.

To make the managerial allocation problem more stark, we assume that the difference in ability between the workers is sufficiently large so that if the manager were socially connected to neither worker, one worker always exerts more effort than the other, regardless of whom is targeted by the manager. We denote the high ability worker by $h$ and the low ability worker by $l$. Formally, ${ }^{16}$

Assumption 1: The ability parameters $\left(\theta_{l}, \theta_{h}\right)$ are such that $\theta_{l}>2 \theta_{h}$, so that worker $h$ 's effort is higher than worker l's for any $\left(m_{l}, m_{h}\right)$.

\footnotetext{
${ }^{16}$ This assumption also implies that the high ability worker would always exert more effort irrespective of whom the manager targets, if the manager were only connected to him or to both workers. The assumption simplifies the analysis by removing regions of the parameter space where there are multiple equilibria for the manager and workers' effort choices in the case where the manager is not socially connected to either worker.
} 


\subsection{The Manager's Allocation Choice}

In our context it is reasonable to assume that the manager observes workers' ability but cannot commit to the allocation of effort ex ante. It then follows that the manager takes the workers' effort choices as given and chooses to allocate her effort between workers $h$ and $l$ to solve the following problem,

$$
\max _{m_{l}, m_{h}} u^{M}=p^{M}\left(m_{l}, m_{h}\right)+\sigma_{l} p_{l}^{W}\left(m_{l}\right)+\sigma_{h} p_{h}^{W}\left(m_{h}\right),
$$

subject to $m_{l}+m_{h}=1$. Substituting for the manager's pay, the workers' pay, and $m_{l}+m_{h}=1$, the manager's problem can be re-written as,

$$
\max _{m_{l}} f+\left(\frac{b}{2}+\sigma_{l}\right)\left(1+k_{l} m_{l}\right) e_{l}+\left(\frac{b}{2}+\sigma_{h}\right)\left(1+k_{h}\left(1-m_{l}\right)\right) e_{h}
$$

The linear structure of (4) implies a corner solution so that the manager will allocate all her effort to either worker $l$ or $h$, depending on which yields the highest marginal return. ${ }^{17}$ The marginal benefit of targeting worker $l$ is equal to $\left(\frac{b}{2}+\sigma_{l}\right) k_{l} e_{l}$ whereas the marginal benefit of targeting worker $h$ is $\left(\frac{b}{2}+\sigma_{h}\right) k_{h} e_{h}$. Assumption 1 guarantees that when the manager is connected to neither worker, $e_{l}<e_{h}$ regardless of the manager's effort choice and this implies that, other things equal, the manager will target the high ability worker. However, differences in the social connections between the manager and the two workers, captured by $\sigma_{i}$ and $k_{i}$, may cause the manager to target the low ability worker instead.

In addition, the managerial targeting choice depends directly on the strength of incentives $b$ and, in equilibrium, also depends on the workers' ability $\theta_{i}$, through the workers' effort choices given by (2). We characterize the solution to the manager's maximization problem in the following two Propositions.

Proposition 1: If the manager is socially connected to the high ability worker only, to neither worker, or to both of them, she targets the high ability worker regardless of the strength of incentives.

Intuitively, when the manager is connected to neither worker, or equally connected to both, social connections do not alter the ranking due to natural ability differences between the two workers. In this case, as the manager cares equally about the earnings of both workers, she will chose whom to target to maximize average productivity and hence her pay. Given that the complementarity between managerial and worker effort is equally strong for both workers, the only difference between the two is that worker $h$ is naturally more able and puts in more effort regardless of the manager's choice. Hence targeting worker $h$ is a dominant strategy for the manager.

\footnotetext{
${ }^{17}$ This property would of course be retained if the manager also choose the level of her effort and not only its allocation across workers.
} 
When the manager is connected to the high ability worker only, the ability differential, the complementarity differential, and the social preferences of the manager, all make the marginal return of targeting worker $h$ higher than the marginal return of targeting worker $l$.

On the other hand, when the low ability worker is socially connected whereas the high ability worker is not, the manager faces a trade-off between targeting the worker she is connected to and the worker whose productivity is highest. The terms of the trade-off depend on the strength of social connections and of incentives, as given by the next result.

Proposition 2: If the manager is socially connected to the low ability worker, she targets him if the effect of social connections on the complementarity between managerial and worker effort is sufficiently strong, if the weight the manager puts on the connected worker earnings is sufficiently high, or if managerial incentives are sufficiently low powered.

The solution is illustrated in Figure 1 in $\left(\frac{\sigma}{b}, k\right)$ space. In the top right hand corner, the unique equilibrium is such that the manager targets her effort towards the connected worker $l$, that is $\left(m_{l}=1, m_{h}=0\right)$. Intuitively, this occurs when managerial incentives are low powered ( $b$ low) and the effect of social connections either on productivity or on the manager's payoff is strong ( $k$ high, $\sigma$ high).

At the other extreme, in the bottom left hand side corner, the unique equilibrium is such that the manager targets all her effort towards the high ability worker, that is $\left(m_{l}=0, m_{h}=1\right)$. Intuitively, this occurs when managerial incentives are high powered ( $b$ is high) and the effect of social connections either on productivity or on the manager's payoff is weak ( $k$ low, $\sigma$ low). Finally in the intermediate range of parameters, the manager does not have a dominant strategy and both allocations of managerial effort are equilibria as the manager's action is the best response to the workers' choices and vice versa. ${ }^{18}$

\subsection{The Manager's Choice versus the Productivity Maximizing Choice}

We now show that social connections can increase, decrease, or leave the firms' productivity unchanged depending on the strength of the complementarity between the manager's and connected worker's effort, which workers are connected, and the strength of managerial incentives.

Proposition 3: The existence of social connections increase the firm's overall productivity if the manager is connected to the high ability worker or if the effect of social connections on the complementarity between the manager's and the connected worker's effort $\left(k_{i}\right)$ is sufficiently strong. When the manager is only connected to the low ability worker and the effect of social

\footnotetext{
${ }^{18}$ Note that if the manager could commit to an allocation ex ante and hence internalize the effect of her actions on workers' effort choice, this region would disappear as the manager would choose the allocation that maximizes her utility.
} 
connections on the complementarity is weak, the existence of social connections weakly decrease the firm's productivity.

When the manager is socially connected to both workers or only to the high ability worker, the firm's productivity is maximized when the manager targets the high ability worker. From Proposition 1 it follows that in this case, the manager's and the firm's interests are aligned, as the manager's utility is also maximized by targeting the high ability worker. The existence of social connections makes the complementarity between managerial and worker effort stronger, which increases productivity both directly, and indirectly by increasing the worker's chosen effort.

When the manager is socially connected to the low ability worker, targeting the low ability worker maximizes average productivity if and only if $(1+k)^{2}>1+3 \frac{\theta_{l}}{\theta_{h}}$, namely if the relative strength of the complementarity between the manager and the connected worker is strong enough to overcome the fact that the connected worker is of lower ability $\left(\frac{\theta_{l}}{\theta_{h}}>1\right)$.

In Figure 1, the productivity maximizing choice is illustrated by the vertical line at $(1+k)^{2}=$ $1+3 \frac{\theta_{l}}{\theta_{h}}$. Figure 1 thus shows that when the complementarity is strong, that is to the right of the line, targeting worker $l$ maximizes average productivity and the existence of social connections is good for the firm. When the complementarity is weak, however, there are cases in which the manager chooses to target the low ability worker, whereas targeting the high ability worker would lead to higher average productivity. This is more likely to happen when managerial incentives are low powered ( $b$ low) or when the manager places greater weight on the earnings of the connected worker $(\sigma$ high). Finally, when the complementarity is weak and either incentives are strong or the social weight is small, the manager targets the high ability worker, and social connections do not affect the firm's productivity.

\subsection{Implications}

The theoretical framework highlights that the effect of social connections on the productivity of connected workers is non-negative. It is positive when the manager targets all her effort to the connected worker. Other things equal, this is more likely to occur when - (i) the effect of social connections on the complementarity between manager and worker effort is strong; (ii) managerial incentives are low powered; (iii) the other worker is not connected.

The theoretical framework also highlights that the existence of social connections can be beneficial or detrimental for the firm's overall productivity, depending on the strength of managerial incentives, and the strength of the complementarity between managerial effort and the effort of the connected worker. When the complementarity effect is strong, social connections increase average productivity regardless of the incentive scheme in place. When the complementarity effect is weak and the manager is connected to the low ability worker, social connections decrease average productivity if managerial incentives are low powered. Social connections can thus be detrimental 
for the firm's productivity if their existence distorts the allocation of managerial effort in favor of low ability but socially connected workers.

In what follows, we empirically analyze the effect of social connections on the productivity of individual workers both when their managers are paid fixed wages and when their pay depends on the average productivity of workers. As illustrated above, this comparison also allows us to establish the effect of social connections on overall firm performance as a function of the managerial incentive scheme in place.

\section{Data, Descriptives, and Empirical Method}

\subsection{Data Sources}

The firm's personnel records are our main data source. These records contain three types of information. First, they list each worker's productivity on every field-day they pick fruit. Productivity is defined as the kilograms of fruit picked per hour, and is electronically recorded with little measurement error. Second, they allow us to identify all the workers and managers present on each field-day. Finally, they contain information on each individual's nationality, date of arrival, and accommodation location on the farm.

Throughout, we analyze data on the main fruit type on the farm, focus on the main farm site during the peak picking season from May 1st until August 31st, and restrict the sample to fields that were picked at least one week either side of the change in managerial incentives. ${ }^{19}$ The sample contains 14439 worker-field-day productivity observations from 241 field-days. This covers 393 workers, 10 managers, 13 fields, and 94 days. As part of our experimental design, the change in managerial incentives occurred midway through the peak season - June 27th - so there are 43 days in the pre-bonus period and 51 days post-bonus.

\subsection{Measuring Social Connections}

We measure social connections between managers and workers along three dimensions - nationality, time of arrival on the farm, and the location on the farm where individuals reside during the season.

The first measure defines a worker and manager to be connected if they are of the same nationality, based on the assumption that people are more likely to befriend others who come from the same country and share the same mother tongue. Given that individuals are hired seasonally from eight Eastern European countries, we observe considerable variation along this

\footnotetext{
${ }^{19}$ Fields are located on two sites on the farm, of which we only use the largest for the analysis as fruit in the smaller site began to ripen only after the introduction of the managerial performance bonus scheme.
} 
dimension..$^{20}$

The second measure of social connections is based on the time that individuals arrive on the farm. This varies across individuals for reasons that are exogenous to the worker's performance on the farm, such as their university term dates in their home countries and the date on which their work permit is issued. On arrival, individuals are consecutively assigned a worker number and then attend an induction programme with others that have arrived at a similar time. Hence the first group of people that a given individual is exposed to, and may form social ties with, are those that arrive on a similar date. If two individuals have a worker number within the same ten digit window, we define the two to be socially connected through their arrival cohort.

The third measure of social connections is based on the geographic location where individuals live during their stay on the farm. Each worker lives in a caravan with up to five others, and each caravan is assigned a unique number. On the main farm site caravans are arranged around a communal space and numbered consecutively from 1 to 46 . We define two individuals to be socially connected through their living site if they live within five caravan numbers of each other. ${ }^{21}$ The underlying assumption is that individuals are more likely to form social ties with their neighbors.

The advantage of using these three exogenous predictors of friendship rather than any direct measure of friendship ties is that the latter are likely to be endogenously determined by manager and worker behavior in the workplace, and also likely to capture the effect of unobservables that determine both the formation of friendship and worker productivity.

Most workers in our sample are connected to at least one of the ten managers. Of the 14439 worker-field-day observations in our sample, 12287 correspond to workers that are socially connected to managers along some dimension. Two points should be noted. First, on observables such as age, gender, and previous work experience, unconnected workers are not significantly different to connected workers. Second, to identify the causal effect of social connections on worker performance we exploit the within worker variation across field-days, in social connections between him and his managers. Those workers that are not connected to any of the managers do not therefore contribute to the estimated parameters of interest. Hence for the main analysis we focus attention on those workers that are socially connected to at least one manager on the farm.

We combine the information on social connectivity along these three dimensions as follows. We define $c_{i j}=1$ if worker $i$ and manager $j$ are connected along any dimension, and 0 otherwise. If there are $M_{f t}$ managers present on the field-day, the share of managers the worker is connected to on the field-day is,

$$
C_{i f t}=\frac{\sum_{j} c_{i j}}{M_{f t}},
$$

\footnotetext{
${ }^{20}$ Among workers, the most common nationality are the Polish (35\%), followed by Ukrainians (29\%) and Bulgarians (10\%). Among managers, $40 \%$ are Polish, 30\% are Bulgarian, and the others are Lithuanian.

${ }^{21}$ There are no opportunities for workers to themselves choose their caravan or worker numbers.
} 
where the summation in the numerator is over all managers $j$ on field-day $f t$.

On most field-days there are between 2 and 4 managers and between 40 and 80 workers present. $^{22}$ While each worker is assigned to only one manager, we do not know the exact matching of workers to managers within the field. We thus interpret (5) as the probability that worker $i$ is connected to his manager on field-day $f t$.

This measure of connectivity varies within a worker over field-days as the identity of his managers over field-days changes. To compare field-days in which worker $i$ is surely not connected to his manager, to field-days in which he is connected with positive probability, we define the dummy variable $D C_{i f t}$, which equals one if $C_{i f t}>0$, and is zero otherwise. This measures whether a worker is connected, in any way, to any of his managers on the field-day. Finally, to assess whether the three dimensions of connectivity are equally relevant we define measures of connectivity $C_{i f t}^{k}$ along each dimension $k$, between worker $i$ and managers on the field-day. We use these alternative measures of social connections $-C_{i f t}, D C_{i f t}$, and $C_{i f t}^{k}-$ at various stages of the analysis.

\subsection{Descriptives}

Table 1 reports descriptive statistics for our variable of interest $C_{i f t}$, the share of managers worker $i$ is connected to on field-day $f t$. The first row shows that, on average, a worker is socially connected to .433 managers on a given field-day when managers are paid fixed wages. The share is almost identical (.439) when managers are paid performance bonuses, suggesting that the process by which managers and workers are allocated to fields does not change over the two halves of the season.

The empirical analysis exploits the variation in social connections within a worker over time. Table 1 shows the extent of this variation by decomposing the overall variation in social connections into that arising within and between workers. ${ }^{23}$ Reassuringly, at least one third of the overall variation in social connections arises from variation within a worker over field-days, and this is true under both managerial incentive schemes.

The remainder of the table shows the descriptives of social connections along each dimension, $C_{i f t}^{k}$. On average, a worker is socially connected to $31 \%$ of the managers by nationality, to $12 \%$ by

\footnotetext{
${ }^{22}$ The median number of managers and workers is 3 and 59, respectively. Field-days with less than 4 managers account for $83 \%$ of the sample.

${ }^{23}$ For the variance decomposition to sum to the total variance in an unbalanced panel, it is necessary to weight the between component by the number of workers on the field-day, denoted $I_{f t}$. If $N$ denotes the number of observations in the sample and FT denotes the number of field-days, the decomposition of the total variance of social connections $C_{\text {ift }}$, into the within and between components, as reported in Table 2, is,
}

$$
\frac{1}{N} \sum_{f t=1}^{F T} \sum_{i=1}^{I_{f t}}\left(C_{i f t}-\bar{C}\right)=\frac{1}{N} \sum_{f t=1}^{F T} \sum_{i=1}^{I_{f t}}\left(C_{i f t}-\bar{C}_{f t}\right)+\frac{1}{N} \sum_{f t=1}^{F T} I_{f t}\left(\bar{C}_{f t}-\bar{C}\right)
$$


living site and to $5 \%$ by arrival cohort. Along each dimension, there is notable variation in social connections within each worker over field-days.

Throughout we analyze the effect of social connections on worker productivity because, in our setting, this can be directly affected by managers' behavior and because workers' productivity is tied to their earnings given that workers are paid piece rates. Table 2 provides information on how workers' productivity varies by their social connectivity to their manager on the field-day as measured by the dummy variable $D C_{i f t}$, and the managerial compensation scheme in place. The first column shows that on average, worker productivity is $6.95 \mathrm{~kg} / \mathrm{hr}$ when workers are managed by individuals they are unconnected to, and their managers are paid a fixed wage. Under the same managerial incentive scheme, the productivity of the same workers significantly rises by $1.31 \mathrm{~kg} / \mathrm{hr}$ to $8.27 \mathrm{~kg} / \mathrm{hr}$ when they are managed by individuals they are socially connected to. From a baseline average productivity of $7.93 \mathrm{~kg} / \mathrm{hr}$ across all worker observations when managers are paid a fixed wage, this difference corresponds to a $17 \%$ increase in the productivity of the same worker when managed by individuals he is socially connected to, relative to himself when managed by individuals he is not socially connected to.

The second column presents evidence on the same comparison when managers are paid a performance bonus. We find that, on average, the productivity of a worker is no different on fielddays when he is socially connected to his managers to field-days when he is socially unconnected to his managers. The unconditional difference-in-difference in workers' productivity by their social connections to managers and across managerial incentive scheme, is $1.20 \mathrm{~kg} / \mathrm{hr}$, and is significantly different from zero. ${ }^{24}$

Three points are of note. First, differences in worker productivity by social connectivity to managers and managerial incentive scheme translate into similar differences in worker earnings. More precisely, when managers are paid a fixed wage, workers earn, on average, 22.02 more on a field-day when they are managed by individuals they are socially connected to, compared to themselves when they are managed by individuals they are socially unconnected to. Relative to a base pay per field-day of $£ 12.8$, this corresponds to a $16 \%$ increase in earnings. This is quantitatively important both in percentage terms and in absolute terms when aggregated over the season. ${ }^{25}$ When managers are paid performance bonuses, workers' earnings are not significantly different whether they are socially connected to their managers or not. The difference-in-difference

\footnotetext{
${ }^{24}$ The standard errors in Table 2 are calculated from running the OLS regression that corresponds to each of the unconditional differences. We account for the fact that there are multiple observations from each worker by allowing the error terms to be clustered at the worker level.

${ }^{25}$ The average worker picks on two to three fields per day and stays on the farm for 100 days. A back of the envelope calculation suggests that over the course of a season, a worker would earn $£ 500$ more if managers were always paid a fixed wage, and they were always managed by individuals they are socially connected to. Given that workers in our sample live in Eastern Europe and much of their earnings are saved to spend in their home country, the real value of these differences is therefore substantial.
} 
in earnings is $£ 2.08$ per field-day, and is significantly different from zero.

Second, as this effect of social connections only exists when managers are paid fixed wages suggests that such favoritism may be detrimental to the firm's overall performance. If not, then when managers are paid performance bonuses that tie their compensation to the average productivity of workers managed, we would expect the extent of favoritism to increase further if such behavior also raised average productivity.

Third, when managers are paid a performance bonus, the productivity of workers when they are socially unconnected rises to the levels when they are socially connected. Hence the differencein-difference is positive because with the change in managerial compensation scheme, worker productivity when socially unconnected catches up with worker productivity when socially connected.

Reading across the columns, we note there is a significant increase in productivity moving from a regime in which managers are paid a fixed wage, to when they are paid performance bonuses. This increase corresponds to the effect of the introduction of managerial performance pay, and has been analyzed in detail in earlier work (Bandiera et al 2005b). In this paper we focus on understanding the effects of social connections between a worker and his manager, on worker performance. Our identification strategy relies on a within worker comparison under both managerial incentive schemes. Hence the effects of the change in managerial incentives that are common to all workers do not confound the identification of main parameters of interest. We later spell out in more detail the precise assumptions underlying our identification strategy, and in the Appendix we present evidence in favor of these assumptions.

To understand whether there are heterogeneous effects across workers underlying the average differences reported in Table 2, Figure 2 shows graphically how each worker's productivity varies, by social connections to his managers, under each managerial incentive scheme. Figure 2a shows that when managers are paid a fixed wage, in general, a worker has higher average productivity on field-days when managed by individuals he is socially connected to, relative to himself on field-days when managed by individuals he is socially unconnected to. Namely, the bulk of workers lie well above the $45^{\circ}$ line. In contrast, Figure $2 \mathrm{~b}$ shows that when managers are paid a performance bonus, the average productivities of workers are not systematically higher or lower on field-days when they are socially connected to their managers relative to field-days when they are not. Namely, worker productivities are equally dispersed around the $45^{\circ}$ line. 


\subsection{Empirical Method}

To identify whether social connections affect worker's productivity, and how this depends on the managerial compensation scheme in place, we estimate the following panel data regression,

$y_{i f t}=\alpha_{i}+\lambda_{f}+\gamma_{0}\left(1-B_{t}\right) \times C_{i f t}+\gamma_{1}\left(B_{t} \times C_{i f t}\right)+\rho B_{t}+\sum_{k} \sum_{d \in N_{k}} \tau_{d}^{k}\left(B_{t} \times D_{i d}^{k}\right)+\sum_{s \in M_{f t}} \mu_{s} S_{s f t}+\delta X_{i f t}+\eta Z_{f t}+u_{i f t}$

where $y_{i f t}$ is worker $i$ 's productivity on field $f$ and day $t$. The worker fixed effects $\alpha_{i}$ account for permanent differences across workers in their productivity, such as those arising from innate ability or motivation, and the field fixed effects $\lambda_{f}$ capture permanent differences in the level of productivity across fields, such as soil quality. ${ }^{26}$

$C_{i f t}$ is the share of managers worker $i$ is socially connected to on the field-day, as defined in (5). $B_{t}$ is a dummy variable equal to one after the performance bonus is introduced (June $27 \mathrm{th}$ ), and zero otherwise. Hence $\left(1-B_{t}\right) \times C_{i f t}$ measures social connections when managers are paid a fixed wage, and $\left(B_{t} \times C_{i f t}\right)$ measures social connections when managers are paid a performance bonus. By also including the bonus dummy variable $B_{t}$ itself, we capture any effect of the change of managerial incentives that is common to all workers.

The coefficients of interest throughout are $\gamma_{0}$ and $\gamma_{1}$. The null hypothesis is that connections do not affect productivity, so $\gamma_{0}=\gamma_{1}=0$. As highlighted by theory, there are a number of plausible alternative hypotheses. If for example the use of social connections reduces average productivity then this type of behavior should be mitigated under performance bonuses so that $\gamma_{0}>\gamma_{1} \geq 0$. Alternatively, if the use of social connections increases average productivity then this type of behavior should be exacerbated under performance bonuses so that $\gamma_{1}>\gamma_{0} \geq 0$.

The inclusion of the worker fixed effects $\alpha_{i}$ allows us to address the concern that unobservable time invariant worker characteristics drive both social connections to managers and worker performance. The effect of social connections $\gamma_{0}$ and $\gamma_{1}$ are thus identified from variation in the level of social connections to managers, within the same worker over different field-days.

However, since connectivity is defined along nationality, living site, and arrival cohort, $\gamma_{0}$ and $\gamma_{1}$ might be biased if, for example, the introduction of the bonus has different effects on workers of different nationalities. This is because the connection measure $C_{i f t}$ would then also be picking up any differential effect of the performance bonus by worker nationality. Obviously, similar concerns arise if workers are differentially affected on the basis of their living site or time of arrival on the farm once managerial performance bonuses are introduced.

To address these concerns we control for a set of interactions between the performance bonus

\footnotetext{
${ }^{26}$ If this specification is estimated only with worker fixed effects, they explain $25 \%$ of the variation in worker productivity, suggesting there is considerable heterogeneity across workers. Estimating the specification only conditional on field fixed effects explains $11 \%$ of the overall variation.
} 
dummy $B_{t}$ and the complete set of nationality, arrival cohort and living site dummies. We define the dummy variable $D_{i d}^{k}=1$ if worker $i$ is of type- $d$ along dimension $k$, and 0 otherwise, and $N_{k}$ denotes the total number of types along dimension $k$. For example, when $k$ is nationality, $D_{i d}^{k}=1$ when the worker is of nationality $d$ and $N_{k}$ is equal to eight as this is the number of different nationalities in our data. These interactions flexibly control for any heterogenous effect on workers of the change in managerial incentives along these dimensions. Hence we estimate the effect of the within worker variation in social connectivity conditional on any heterogeneous effects between workers that may arise as managers respond to the introduction of performance bonuses along other margins apart from those arising from social connections with their subordinates.

$S_{s f t}$ is a dummy equal to one if manager $s$ works on field $f$ on day $t$, and zero otherwise, and $M_{f t}$ is the set of managers that work on the field-day. Hence $\sum_{s \in M_{f t}} \mu_{s} S_{s f t}$ in (6) corresponds to a full set of manager dummies. These control for time invariant traits of each manager, such as their ability to motivate workers and their management style, that affect the performance of managed workers. These allow us to address the concern that there are unobservable managers' characteristics that drive both their social connections and the performance of their subordinates.

$X_{\text {ift }}$ captures worker $i$ 's time varying characteristics. This includes the worker's picking experience, defined as the cumulative number of field-days they have picked fruit on the farm. $Z_{f t}$ captures time-varying field characteristics. This includes the field's life cycle, defined as the $n$th day the field is picked divided by the total number of days the field is picked over the season. This captures the natural within-field trend in productivity as fields deplete over time. We also include a time trend to capture learning by farm management and any aggregate trends in productivity. ${ }^{27}$

Finally, we note that the social connections between a worker and his managers are unlikely to be identically and independently distributed within a worker over field-days. We therefore adopt a conservative strategy in estimating standard errors and allow the disturbance terms $u_{i f t}$ to be clustered by worker throughout. ${ }^{28}$

\subsection{Identifying Assumptions}

We identify the effect of social connections on worker productivity by exploiting the within worker variation in social connections to his manager over field-days, and by exploiting the experimental variation in managerial incentives, as discussed in Section 2. There are two underlying identifying assumptions related to these two sources of variation.

\footnotetext{
${ }^{27}$ As fields are operated on at different parts of the season, and not all workers pick each day, the effects of the field life cycle and workers' picking experience can be separately identified from that of the time trend. The average field life cycle is not significantly different under the two managerial compensation schemes.

${ }^{28}$ Clustering the disturbance terms $u_{i f t}$ by field-day - say because workers on the same field-day face common productivity shocks - leads to the standard errors on the parameters of interest, $\gamma_{0}$ and $\gamma_{1}$, being considerably smaller than those we report.
} 
The first is that unobservable determinants of workers' allocation to managers are orthogonal to the managerial incentive scheme in place. As discussed in Section 2.2, the within worker variation in social connections is exogenous to the behavior of workers and managers because the allocation of individuals to fields is determined by the COO, based on the demand for labor for picking and non-picking tasks across fields. Nevertheless workers' allocation to managers might still depend on factors that affect performance and are observable to the COO but not the econometrician.

To provide support for this assumption, Tables A1 and A2 present evidence that the allocation rules do not change with the change in managerial incentives. First we compare the allocation of the connected workers we use for our analysis, to the allocation of unconnected workers. Table A1 estimates conditional logit regressions of the probability that, conditional on working, worker $i$ is selected to pick fruit on day $t$, versus being selected for non-picking tasks. We also estimate the probability of, conditional on not picking, worker $i$ being chosen for non-picking tasks versus being left unemployed on day $t$. Reassuringly, we find that when performance bonuses are introduced, neither probability changes differentially for socially connected and unconnected workers.

Second, we show that field-day and worker-field-day specific determinants of productivity do not predict the level of social connections $C_{i f t}$ differently under the two managerial incentive schemes. More precisely, in Table A2 we estimate regressions of the form,

$$
C_{i f t}=\alpha_{i}+\lambda_{f}+v B_{t}+\left[\left(\phi_{0}+\phi_{1} B_{t}\right) \times X_{i f t}\right]+\left[\left(\varphi_{0}+\varphi_{1} B_{t}\right) \times Z_{f t}\right]+\sum_{s \in M_{f t}} \mu_{s} S_{s f t}+u_{i f t}
$$

where $B_{t}$ is the bonus dummy, $X_{i f t}$ captures worker $i$ 's time varying characteristics and $Z_{f t}$ captures several time-varying field characteristics. Our identifying assumption requires $\phi_{1}=\varphi_{1}=$ 0. Table A2 reports the p-values of the t-tests on each interaction variable and on the joint F-test of their significance. Reassuringly, we fail to reject the null of zero coefficients in all cases. ${ }^{29}$

The second identifying assumption is that any effect of social connections on individual productivity unrelated to the managerial incentive scheme in place, remains unchanged over time. We later address this concern by allowing the effects of social connections to vary over time. In particular we estimate whether the effects of social connections vary - (i) across the first and second halves within each managerial incentive scheme (effectively dividing the season up into quarters); (ii) with the field's life cycle; (iii) with the time the worker has been present on the farm. In each

\footnotetext{
${ }^{29}$ Three other pieces of evidence also suggest that farm operations do not change over the two halves of the season. First, the ratio of workers to managers does not change significantly over the two halves of the season and remains at 20 throughout. Second, at the field-day level, the average share of workers that are socially connected to managers does not change significantly over the two halves of the season, nor does the variation in this share between fields on the same day. This suggests workers do not become sorted into fields by social connections over time. Third, using the estimated worker fixed effect from (6), $\widehat{\alpha}_{i}$, as a measure of a worker's ability, we find that groups of workers on the field-day are equally heterogeneous before and after the change in managerial incentives. Hence there is no evidence the COO sorts workers differently by ability into fields post-bonus.
} 
case we find no evidence that the effects of social connections on individual productivity change over time with these three factors. Rather there is a discontinuous effect of social connections on worker performance that occurs precisely at the time when managerial incentives are exogenously altered as part of the experimental research design.

\section{Empirical Analysis}

\subsection{Baseline Results}

Table 3 presents estimates of our baseline specification (6). In Column 1 we measure social connections with the dummy variable $D C_{i f t}$ which identifies whether a worker is connected, in any way, to any of his managers on the field-day. This is the variable used for the unconditional difference-in-difference in Table 2. The results show that the pattern of unconditional differences in worker productivity by social connections and managerial incentive scheme reported in Table 2 , are robust to conditioning on a rich set of determinants of worker productivity. The result in Column 1 shows that when managers are paid a fixed wage, the average worker has significantly higher productivity on field-days on which he is socially connected to his managers $\left(\widehat{\gamma}_{0}>0\right)$. When managers are paid performance bonuses, there is no effect on the average worker's productivity of being more socially connected to her managers on the field-day $\left(\widehat{\gamma}_{1}=0\right)$.

The magnitude of the $\widehat{\gamma}_{0}$ coefficient implies that when managers are paid a fixed wage, being connected to at least one manager on the field, increases productivity by $4 \%$ for the average worker, whereas there is no such effect when managers are paid performance bonuses. As suggested by the descriptive evidence in Table 2, this result is not driven by a lack of within worker variation in social connections to managers under the two managerial incentive schemes.

In Column 2 we use $C_{i f t}$ - the share of managers the worker is connected to by nationality, living site, or arrival cohort - as our measure of social connections. Compared to the dummy variable $D C_{i f t}$, this is a more precise measure as it distinguishes between field-days in which a worker is connected to potentially more than one manager. The pattern of coefficients is the same as in Column 1 but the implied magnitude of the effect is much larger. Evaluating at the mean, the magnitude of $\widehat{\gamma}_{0}$ implies that when managers are paid a fixed wage, the productivity of a worker on field-days when he is socially connected to all the managers on the field relative to his productivity on field-days when he is socially unconnected to managers, will be $.752 \mathrm{~kg} / \mathrm{hr}$ higher, other things equal. Relative to a baseline average worker productivity of $7.93 \mathrm{~kg} / \mathrm{hr}$ when managers are paid fixed wages, this represents a $9.5 \%$ increase in the productivity of connected workers. $^{30}$

\footnotetext{
${ }^{30}$ While these baseline results focus on the effects of social connections on worker productivity, we also explored whether the strength of social ties between a worker and his managers affect worker productivity. We can define
} 
The difference between the estimated $\widehat{\gamma}_{0}$ parameters in Columns 1 and 2 lends support to the idea that managers and workers do not choose who they work with, even within a field-day. Namely, if managers favor socially connected workers and workers could sort across managers within the field, workers should assign themselves to a manager they are socially connected to, if such a manager is present. In that case, however, the effect of being connected to one manager should be no different than being connected to two or more. The fact that the implied effect of being connected to all managers (from Column 2) is almost twice as big as the effect of being connected to at least one (from Column 1), indicates that workers cannot assign themselves to a manager whom they are connected to.

Taken together, this pattern of results suggests the effect of social connections in the workplace is for managers to favor workers they are connected to when their incentives are low powered. At the foot of Columns 1 and 2 we report the implied difference-in-difference estimate, $\left(\widehat{\gamma}_{0}-\widehat{\gamma}_{1}\right)$. In line with the descriptive evidence, this is positive in both cases and significantly different from zero at the $1 \%$ significance level when using the continuous measure of social connections. This suggests that the use of social connections does not maximize the firm's overall performance as measured by average worker productivity because when managers interests become more aligned with those of the firm, the effects of social connections are significantly reduced..$^{31}$

The pattern of coefficients helps rule out three alternative hypotheses of why social connections may matter in this workplace. First, suppose that workers were always assigned to socially connected managers when productivity on the field is exogenously higher. In this case social connections should have the same positive and significant effect under both schemes, i.e. $\widehat{\gamma}_{0}=\widehat{\gamma}_{1}>0 .{ }^{32}$

Second, suppose that when workers are on the field-day with managers they are socially connected to, the marginal utility of leisure is higher because they prefer to socialize with their managers. If so, however, this should be true under both managerial incentive schemes, i.e. $\widehat{\gamma}_{0}=\widehat{\gamma}_{1}<0$.

Third, the pattern of coefficients allows us to rule out the hypothesis that the effect of social

the strength of the social tie as the number of dimensions along which the two are connected, $\sum_{k} D C_{i f t}^{k}$. We find that a worker's productivity is monotonically increasing in the number of dimensions along which he is connected to his managers when his managers are paid a fixed wage, and there is no such effect under performance bonuses. However, these results should be interpreted with caution because, given that each dimension of connectivity is orthogonal to the others, there are only $5 \%$ of observations from which the effects of being connected along strictly more than one dimension can be identified.

${ }^{31}$ We also addressed the concern that social connections of workers are correlated within the same field-date by clustering standard errors at the connection level within each field-date. The baseline results are robust to this alternative clustering.

${ }^{32} \mathrm{~A}$ related concern is that the share of managers a worker is connected to is higher on field-days when there are more managers present. If more managers are present when productivity is expected to be higher this would lead to a spurious correlation between social connections and worker productivity. As a check for this, we find no correlation between the share of managers a worker is connected to and the number of managers on the field-day. This correlation is -.02 when managers are paid fixed wages and .01 when they are paid performance bonuses. 
connections is driven by workers' rather than managers' behavior. Indeed, if workers were to internalize the effect of their effort on their manager's pay when socially connected to her, we would observe workers exerting more effort when this actually affects the manager's pay, namely when the manager is paid the performance bonus, i.e. $\widehat{\gamma}_{0}=0<\widehat{\gamma}_{1}$.

One concern is that the COO intentionally sorts managers and workers into fields on their basis of their social connections. If so, the effect of social connections would be biased downwards. To check for this, we exploit the fact that some dimensions of connectivity, such as nationality, are more easily observable to the COO than others, such as time of arrival. If such sorting biases the estimates, we should find the effect of social connections to be mostly driven by dimensions that are easier to observe. Column 3 then estimates a specification analogous to (6) that separately controls for each dimension of social connectivity, $C_{i f t}^{k}$. We see that when managers are paid a fixed wage, social connections along each of the dimensions have a positive and significant effect on worker productivity.

To compare the magnitudes of the $\widehat{\gamma}_{0}^{k}$ coefficients, we consider the implied effect on worker productivity of a one standard deviation increase in $C_{i f t}^{k}$ from its mean. ${ }^{33}$ We find that when managers are paid a fixed wage, the productivity of a given worker is $4.7 \%, 1.6 \%$ and $2.5 \%$ higher when the share of managers he is connected to by nationality, living site, and arrival cohort respectively, is one standard deviation higher. Social connections along any dimension do not affect worker productivity when managers are paid a performance bonus. ${ }^{34}$

A second concern is that the difference-in-difference estimate of social connections might be picking up any heterogeneous effects of the managerial bonus scheme across workers. Indeed, in earlier work (Bandiera et al 2005b) we have shown that managers target their effort towards more able workers when performance bonuses are introduced, and this explains changes in the productivity between workers under the two managerial incentive schemes. If worker ability is correlated to our measure of social connections to managers, the difference-in-difference estimate would be biased.

To take account of this we introduce a complete set of interactions between each worker's fixed effect and the performance bonus dummy. This is the most general way to capture differential effects across workers of the change in managerial incentives. The result, reported in Column 4, shows that the magnitude and significance of the parameters of interest are similar to those in the

\footnotetext{
${ }^{33}$ Table 1 shows there are differences in the mean and standard deviation of each measure of social connectivity.

${ }^{34}$ We chose to measure social connections along the dimensions of nationality, living site and time of arrival in order to capture social links that form for different reasons and, indeed the correlation among the three measures $C_{i f t}^{k}$ is very low. We therefore expect their estimated effect on productivity to be the same, regardless of whether they are included together or one at the time. Appendix Table A3 controls for the share of managers worker $i$ is connected to along dimension $k\left(C_{i f t}^{k}\right)$ in (6). We find the pattern of the $\left(\widehat{\gamma}_{0}^{k}, \widehat{\gamma}_{1}^{k}\right)$ coefficients to be similar to those reported in Column 3. In addition the implied difference-in-differences, $\left(\widehat{\gamma}_{0}^{k}-\widehat{\gamma}_{1}^{k}\right)$, are positive and significantly different from zero at conventional levels in all cases.
} 
baseline estimates.

The final specification addresses the concern that there may be factors at the field-day level that create a spurious correlation between social connections and productivity. For example, managers might lobby the $\mathrm{COO}$ to be allocated workers they are connected to on field-days when productivity is exogenously higher. To address this concern the final specification includes fieldday fixed effects. The effects of social connections $C_{i f t}$ under each managerial incentive scheme are then identified off the variation across workers in the same field-day in the level of their social connections in deviation from the workers' average level of social connections under each managerial compensation scheme. The result in Column 5 shows the previous results to be robust to conditioning on factors that vary across field-days, such as managers lobbying for workers, field conditions, the hours worked on the field-day, or the level of the piece rate for workers.

Finally, we perform a falsification exercise based on measures of social connectivity that are purely spurious. These are based on whether the worker and manager have the same - (i) initial on their first name (A-Z); (ii) day of month of birth (1-31); (iii) day of week of birth (MondaySunday). The results of this falsification exercise are presented in Table A4. Reassuringly, we find that these spurious measures of social connection have no effect on worker productivity under either managerial incentive scheme. ${ }^{35}$

\subsection{Econometric Concerns}

\subsubsection{Time Varying Factors}

The first set of econometric concerns relates to the assumption that any effect of social connections on individual productivity unrelated to the managerial incentive scheme in place, remains unchanged over time. If not, then $\widehat{\gamma}_{0}$ and $\widehat{\gamma}_{1}$ may simply pick up that the effect of social connections naturally dies out over time, rather than because managers change their behavior when they are paid performance bonuses. For example, managers may initially favor some workers in order to befriend them. Similarly workers may initially work hard under some managers in order to befriend them. This would explain the pattern of coefficients we find in the data and suggests that favoritism is not a long run equilibrium phenomenon.

In Table 4 we analyze whether the effects of social connections on worker productivity naturally disappear over time. In Column 1 we split both the pre and post performance bonus periods into halves and allow the effect of connections to change within the pre and post bonus periods. Intuitively, if the effect of social connections were naturally declining over time we would expect it to be higher in the first half of the pre-bonus period than in the second half, and again, higher in

\footnotetext{
${ }^{35}$ We defined these spurious measures of social connections along these three dimensions in particular because their mean value, and variation between and within workers, by managerial incentive scheme, are similar to those for the living site and arrival cohort based measures actually used in the analysis.
} 
the first half of the post-bonus period than in the second half. Column 1 shows that, in contrast, there is no change in the effect of social connections within each period. Rather the effect of social connections on worker productivity disappears discontinuously with the introduction of the performance bonus for managers.

A second concern is that $\widehat{\gamma}_{0}$ and $\widehat{\gamma}_{1}$ might pick up that later in the field life cycle there is less variation in the fruit available across different rows, and so managers have no means by which to favor connected workers, even though they prefer to do so. To check for this, in Column 2 we allow the effect of social connections to vary with a field specific time trend - the field life cycle. We find no evidence that the effect of social connections diminishes within a field over time.

A third time related concern is that the true social ties between a worker and his managers are measured with error using $C_{i f t}$ which is based on three particular dimensions. This measurement error is non-classical because it increases over time if workers learn they are better off being socially connected to managers, and so invest more into forming social ties with managers over time, irrespective of whether they are of the same nationality, living site, and arrival cohort. If so, we should find the effect of $C_{i f t}$ to diminish with the time the worker has spent on the farm. In Column 3 we allow the effect of social connections to vary with a worker specific time trend the number of days the worker has been present on the farm. There is no evidence the effect of social connections diminishes as a worker spends more time on the farm.

Finally in Column 4 we present a placebo test using fields that were picked on only after the introduction of the performance bonus and are therefore excluded from our main sample. Given that in our sample the bonus is introduced when the average (and median) field is half the way through its life cycle, we define a placebo bonus dummy to be equal to zero if the field is in the first half of its life cycle and equal to one if it is in the second half. The results in Column 4 indicate that social connections have no effect on worker productivity either side of the placebo dummy, thus ruling out that our previous results were due to the effect of social connections naturally disappearing once fields have reached half of their life cycle.

Overall, the evidence in Table 4 indicates that the effect of social connections does not decline smoothly with time, field specific trends, or worker specific trends. Rather there is a discontinuous effect of social connections on worker performance at the time when performance bonuses were introduced. Given that we had full control over the timing of this change, our experimental research design ensures that the exact date on which the managerial incentive schemes changed is uncorrelated with any determinants of individual productivity.

\subsubsection{Sample Selection}

A second set of econometric concerns relate to the composition of workers in the sample and how

this may differ under the two halves of the season. Consider first the issue that the group of 
workers available to pick fruit is changing over time because workers arrive and leave the farm on different dates. If workers that arrive early in the season when managers are paid a fixed wage then leave in the second half of the season, a different group of workers is used to estimate the within worker estimates $\gamma_{0}$ and $\gamma_{1}$.

Some of the reasons why workers arrive and leave at different times - such as differences in university term dates and the date on which their work permit is issued - are orthogonal to their performance. However there remain concerns that workers who arrive early in the season are different to those that arrive later. For example, they may be able to form stronger social ties with managers because there are fewer other workers present earlier in the season. If so our measure of social connections $C_{i f t}$ is measured with error in the second half of the season, leading to attenuation bias in $\widehat{\gamma}_{1}$.

To address this concern Column 1 of Table 5 restricts the sample to workers that are present and available to pick fruit for three weeks either side of the change in managerial incentives. When the same group of workers are then used to identify $\gamma_{0}$ and $\gamma_{1}$, we find the significance and magnitude of these estimates to be similar to those in the baseline specification. The pattern of results also remains unchanged in Column 2 where we restrict the sample to workers that are observed picking under both managerial incentive schemes.

A second issue is that conditional on being present on the farm, the group of workers selected to pick fruit changes over the two halves of the season. In Bandiera et al (2005b) we show that with the introduction of the performance bonus scheme, worker productivity rises so that fewer workers are required to pick the same overall quantity of fruit. We find that workers of higher ability are then more likely to be selected to pick fruit in the first place. This is of concern if for example, low ability workers work harder in order to befriend managers they have similar characteristics to on the field-day, and these workers pick predominantly in the first half of the season. This would cause $\widehat{\gamma}_{0}$ to be biased upwards. To address this concern Column 3 of Table 5 restricts the sample to those workers that are chosen to pick for at least six days under both managerial incentive schemes. We find the significance and magnitude of the parameters of interest to be similar to those in the baseline specification.

\subsection{Social Connections and the Firm's Overall Performance}

The finding that being socially connected to managers increases the productivity of the average worker when managers are paid fixed wages whereas social connections do not affect productivity when managers are paid performance bonuses indicates that in our context, favoring connected workers does not maximize the firm's average productivity. As managers stop favoring connected workers once their pay depends on average productivity, this indicates that favoring connected workers could have not been maximizing the firm's average productivity in the first place. 
Since we do not observe managers working only with unconnected workers, we cannot quantify the effect of social connections and whether the existence of social connections is detrimental to the firm's productivity when managers are paid fixed wages. However, the theoretical framework makes clear that social connections can reduce average productivity when - (i) the effect of social connections on the complementarity between manager and worker effort is weak $\left(k_{i}\right.$ is close to one when $\sigma_{i}=\sigma$ ); (ii) the manager is connected to some but not all the workers; and, (iii) favors are rival, namely if the manager devotes time to help one worker he has less time to devote to the others. In what follows we present evidence on whether these conditions hold in our setting.

First, we expect social connections to strengthen the complementarity between manager and worker effort because they can reduce informational asymmetries, facilitate joint problem solving, and provide managers the ability to motivate workers through social rewards and punishments. In our context, however, the tasks workers are undertaking are relatively simple so any potential benefits that social connections have for problem solving or improved communication more generally, are likely to be small. In addition, workers face high powered monetary incentives, so that the scope for the manager to exploit social connections to provide further incentives through social punishments or rewards is rather limited.

Second, the distribution of social connections among workers in our sample is such that condition (ii) is verified on all field-days. On average, $60 \%$ of workers on the field-day are connected to at least one manager on a given field-day. In addition, the mean and variance of the share of workers connected to managers on the field-day do not differ significantly under the two managerial incentive schemes.

Third we seek to establish whether managerial effort is a rival good in the sense that if the manager decides to target her effort towards one worker, she necessarily does so at the expense of another worker. More precisely, if favors are rival, the effect of social connections on the productivity of worker $i$ should be smaller when the share of his co-workers who are also connected to managers, increases. In short, if few workers are connected, the manager can devote all of her time to favor them. If more workers are connected, the manager needs to spread her favors more thinly.

To shed light on this we re-estimate our baseline specification (6) and allow the effect of social connections on the productivity of worker $i$ on field day $f t$ to vary with the share of workers who are also connected to a manager on field day $f t$. We first consider social connections and competition for favors in terms of the dummy variable measure $D C_{i f t}$. Namely, we measure the competition for favors by the share of workers who are connected to at least one manager on the same field-day as worker $i$. This is given by $\frac{1}{N_{f t}} \sum D C_{i f t}$ where $N_{f t}$ is the number of workers on the field-day and the summation is taken over all such workers $i$.

For ease of comparison, Column 1 of Table 6 replicates the baseline specification of Column 1 
in Table 3. Column 2 then introduces the interaction effect of social connections with this measure of competition for favors. The result supports the hypothesis that when a greater share of workers present are socially connected to managers, the effect of connections on the productivity of each connected worker is smaller. When managers are paid fixed wages, social connections increase the productivity of a connected worker by $13 \%$ if the share of connected workers on the field is $25 \%$, by $8 \%$ if the share of connected workers on the field is $50 \%$, by $4 \%$ if the share of connected workers is $75 \%$, and zero if all workers are connected.

Two points are of note. First, as theory suggests, when all workers are connected the manager cannot redistribute effort from unconnected to connected workers, hence the effects of social connections are zero. Second, the share of workers connected on the field-day does not have a direct effect on productivity. This further supports the identifying assumption that the allocation of workers and managers to fields is uncorrelated to the average productivity on the field-day. If it were, then we would expect worker productivity to be positively correlated with the share of socially connected workers present on the field-day

In the next two Columns we measure social connections using the continuous measure, $C_{i f t}$. We measure competition for favors by the average level of social connections of workers on the field-day, as given by $\frac{1}{N_{f t}} \sum C_{i f t}$. Column 3 again reports the baseline specification in Column 2 of Table 3 for comparison. In Column 4 we interact the level of social connections with the measure of competition for favors. We again find that when managers are paid fixed wages, the effects of social connections are significantly weaker when the average level of social connectivity of other workers on the field-day is higher. The elasticity of productivity with respect to the probability of being connected to a manager is .19 when the average co-worker is connected to a quarter of the managers, .09 when co-workers are connected to half the managers, and zero when co-workers are connected to three quarters of the managers. Again, we find no evidence of such heterogenous effects of social connections when managers are paid a performance bonus.

This finding sheds light on the mechanism behind why exploiting social connections across tiers of the firm hierarchy may be detrimental to overall firm performance. On field-days in which connected workers are of high ability, social connections reinforce managerial incentives to target high ability workers. There is therefore no tension between the allocation of managerial effort that maximizes the manager's utility and that which maximizes average productivity overall.

On the other hand, on field-days in which connected workers are of low ability and unconnected workers are of high ability, in order to favor connected workers the manager distorts her effort away from unconnected workers of higher ability. In this case, the existence of social connections is detrimental to the firm's performance. 


\section{Discussion}

We provide evidence on the interplay between social connections, incentives, and productivity within a firm. We show that in a setting where managerial effort can be targeted to affect the productivity and earnings of individual workers, the existence of social connections between individuals at different tiers of the firm hierarchy affects individual and firm performance.

We find that social connections give rise to favoritism, but only when managerial incentives are low powered. Favoritism increases the productivity of the connected workers but is suboptimal for the firm's average productivity.

Our results bring new evidence to the small but growing literature that highlights the importance of social relationships in the workplace. Our findings indicate that managerial behavior is shaped by both their social connections with their subordinates and their monetary incentives. Both factors are key to explaining the success of existing incentive structures and to guide the design of optimal compensation schemes for both workers and managers.

The use of detailed personnel data combined with the purely exogenous variation created by our natural field experiment allows us to precisely identify the causal effect of social connections between workers and managers on the performance of individual workers, and on firm performance overall. Precision, however, inevitably comes at the cost of a loss of generality, because the firm we study, as any other, has unique features that shape social connections between workers and managers and their effect on productivity. The following features of this work environment are particularly noteworthy for the external validity of this study.

First, managers and workers are of similar ages and backgrounds and they live on the farm site for the entire duration of their stay. Both features increase the likelihood that they form strong social connections with one another. In other settings, social connections might be less likely to form or to be strong enough to affect behavior. On the other hand, the workers in this study are employed on short term seasonal contracts and so long run social ties are less likely to form relative to other firms.

Second, in our setting managers can help workers by allocating them to better rows, by reallocating them quickly to new rows, and by providing them with new crates as soon as needed. To the extent that favoritism is disapproved of by unconnected workers, the fact that these actions are observable by all workers reduce the managers' ability to favor their friends. Namely we expect the effect of social connections and favoritism to be stronger in settings where favoritism by managers is more easily disguised.

Third, the specific form that the effects of social connections take, depends on the technology and incentive schemes in the workplace. In our context workers are paid piece rates and managers can undertake actions that improve the productivity and hence earnings of connected workers. In other contexts in which workers are paid fixed wages, social connections might be exploited 
to allow subordinates to slack, allocating subordinates to more desirable positions, or helping subordinates be promoted. Moreover, in our context workers' productivity is precisely measured, so there is also no scope for managers to show favoritism through subjective evaluations of workers. In general, managers will have more margins along which to favor workers and all such activities will affect the firm's overall performance.

Perhaps the most important consideration is that while in our context social connections give rise to favoritism that is not optimal for the firm's performance, in other settings social connections might be beneficial. As emphasized throughout, social connections can reduce informational asymmetries, facilitate joint problem solving, and provide managers the ability to motivate workers through social rewards and punishments. In our context, the tasks workers are undertaking are relatively simple and so any potential benefits that social connections have for problem solving or improved communication more generally, are likely to be small. In other settings, the productivity enhancing effects of social connections might dominate the inefficiency due to favoritism. For example Ichniowski and Shaw (2005) present evidence from steel finishing lines - a relatively complex task that involves problem solving - of such positive effects of improved communication within and between tiers of the firm hierarchy. ${ }^{36}$

The fact that managers devote effort to increase the productivity of connected workers, even when they are paid fixed wages, suggests that social connections between managers and workers can provide an alternative, and possibly cheaper, mechanism to the provision of monetary incentives. It may thus be in a firm's best interests to foster social ties between management and workers. Indeed many firms are observed devoting resources towards such bonding exercises. ${ }^{37}$ Relatedly, the fact that managers behave as if they derive utility from helping connected workers, implies that being socially connected to their subordinates lowers the managers' participation constraint and thus the firm's wage bill may be reduced. However, this strategy may be suboptimal if it leads to the self selection of lower quality managers to the firm over time.

More generally, our findings provide support to the idea that interplays between social relationships and incentives need to be taken into account, in order to understand how individuals respond to a given set of incentives, and to understand the optimal set of incentives within an organization. Differences in the social organization of the workplace might therefore explain part of the productivity differences among otherwise observationally similar firms.

\footnotetext{
${ }^{36}$ Relatedly, Nagin et al (2002) present evidence from a field experiment in a call centre that exogenously varied the probability that employees would be monitored by managers. Their results suggest that management's "perceived empathy and fairness" in dealing with employees may play an important role in reducing workplace opportunism. Other beneficial effects of social capital within firms has also been discussed in the sociology literature. These include potentially better hiring outcomes through the use of referrals by current employees (Fernandez et al 2000).

${ }^{37}$ Social connections within firms are just one alternative to using monetary incentives to solve agency problems. There is a growing theoretical and empirical literature on the relationship between intrinsic and extrinsic motivation (Frey and Oberholzer-Gee 1997, Kreps 1997, Benabou and Tirole 2003).
} 


\section{Appendix}

\subsection{Proofs}

Proof of Proposition 1: The marginal benefit of targeting worker $l$ is $\left(\frac{b}{2}+\sigma_{l}\right) k_{l} e_{l}$ whereas the marginal benefit of targeting worker $h$ is $\left(\frac{b}{2}+\sigma_{h}\right) k_{h} e_{h}$. If neither worker is connected, the marginal benefit of targeting worker $i$ is $\frac{b}{2} e_{i}$ and this is larger for worker $h$ since, by Assumption $1, e_{l}<e_{h}$. If both workers are connected, then the the marginal benefit of targeting worker $i$ is $\left(\frac{b}{2}+\sigma\right) k e_{i}$, which again is higher for worker $h$ under Assumption 1. Finally, if the manager is connected only to worker $h$, the marginal benefit of targeting worker $h$ is $\left(\frac{b}{2}+\sigma\right) k e_{h}$ which is higher than the marginal benefit of targeting worker $l$, namely $\frac{b}{2} e_{l}$, both because $\sigma>0, k>1$ and $e_{l}<e_{h}$

Proof of Proposition 2: From (4) we see that the manager targets worker $l$ if $\left(\frac{b}{2}+\sigma\right) k e_{l}>$ $\frac{b}{2} e_{h}$, thus targeting worker $l$ is an equilibrium if and only if $\left(\frac{b}{2}+\sigma\right) k e_{l}\left(m_{l}=1\right)>\frac{b}{2} e_{h}\left(m_{l}=1\right)$. Similarly, targeting worker $h$ is an equilibrium if and only if $\left(\frac{b}{2}+\sigma\right) k e_{l}\left(m_{l}=0\right)<\frac{b}{2} e_{h}\left(m_{l}=0\right)$. Taken together the two conditions imply that;

(i) if $\frac{\sigma}{b}>\frac{\theta_{l} / \theta_{h}}{k}-\frac{1}{2}$ targeting worker $l$ is the unique equilibrium,

(ii) if $\frac{\theta_{l} / \theta_{h}}{2 k(1+k)}-\frac{1}{2}<\frac{\sigma}{b}<\frac{\theta_{l} / \theta_{h}}{k}-\frac{1}{2}$, both targeting worker $l$ and targeting worker $h$ are equilibria,

(iii) if $\frac{\sigma}{b}<\frac{\theta_{l} / \theta_{h}}{2 k(1+k)}-\frac{1}{2}$ targeting worker $h$ is the unique equilibrium.

Figure 1 depicts the two conditions in $\left(\frac{\sigma}{b}, k\right)$ space. The two curves are the $\frac{\sigma}{b}=\frac{\theta_{l} / \theta_{h}}{k}-\frac{1}{2}$ and $\frac{\sigma}{b}=\frac{\theta_{l} / \theta_{h}}{2 k(1+k)}-\frac{1}{2}$ loci. When social connections do not affect the complementarity between managerial and worker effort, namely when $k=1$, the vertical intercept of the former is $\frac{\theta_{l}}{\theta_{h}}-\frac{1}{2}$, and of the latter $\frac{\theta_{l}}{4 \theta_{h}}-\frac{1}{2}$. When the manager does not care about the earnings of the connected worker, namely when $\sigma=0$, the horizontal intercepts of the two loci are $2 \frac{\theta_{l}}{\theta_{h}}$ and $\frac{1}{2}\left(\sqrt[2]{4 \frac{\theta_{l}}{\theta_{h}}-1}-1\right)$ respectively

Proof of Proposition 3: We first show that when the manager is connected to the high ability worker or to both workers, average productivity is higher than when she is connected to neither worker. When the manager is not connected to either worker, by Proposition 1 she targets the high ability worker and average productivity is $\frac{1}{2}\left(\frac{1}{\theta_{l}}+\frac{4}{\theta_{h}}\right)$. When the manager is connected to both, or the high ability worker only, she targets the high ability worker and average productivity is equal to $\frac{1}{2}\left(\frac{1}{\theta_{l}}+\frac{(1+k)^{2}}{\theta_{h}}\right) \geq \frac{1}{2}\left(\frac{1}{\theta_{l}}+\frac{4}{\theta_{h}}\right)$ for any $k \geq 1$.

When the manager is connected to the low ability worker, targeting the low ability worker maximizes average productivity if and only if $\frac{1}{2}\left(\frac{(1+k)^{2}}{\theta_{l}}+\frac{1}{\theta_{h}}\right)>\frac{1}{2}\left(\frac{1}{\theta_{l}}+\frac{4}{\theta_{h}}\right)$, namely, $k>\sqrt[2]{3 \frac{\theta_{l}}{\theta_{h}}+1}-1$. A sufficient condition for the manager to target the low ability worker is $k>2 \frac{\theta_{l}}{\theta_{h}}>\sqrt[2]{3 \frac{\theta_{l}}{\theta_{h}}+1}-1$. Hence for $k>2 \frac{\theta_{l}}{\theta_{h}}$, social connections are beneficial to the firm's average productivity regardless of whether the manager is connected to the high ability worker, the low ability worker, or both. 
When the complementarity is weak, namely when $k<\sqrt[2]{3 \frac{\theta_{l}}{\theta_{h}}+1}-1$, average productivity is maximized by targeting the high ability worker regardless of whom the manager is connected to. However, whether the manager targets the high ability worker depends on the strength of her preferences for the low ability worker $\sigma$, and on the strength of managerial incentives $b$. From the proof of Proposition 2 above we know that when $\frac{\sigma}{b}>\frac{\theta_{l} / \theta_{h}}{k}-\frac{1}{2}$, targeting the low ability worker is the unique equilibrium. In this case social connections reduce average productivity because they distort the allocation of managerial effort in favor of the connected worker who is of low ability. On the other hand, when $\frac{\sigma}{b}<\frac{\theta_{l} / \theta_{h}}{2 k(1+k)}-\frac{1}{2}$ targeting worker $h$ is the unique equilibrium. In this case, the social connection between the manager and worker $l$ has no effect on average productivity.

\subsection{The COO's Allocation of Workers to Tasks}

We present evidence in support of our identifying assumption that the COO's allocation of workers to fields does not change differentially across the two managerial incentive schemes for socially connected and unconnected workers. More precisely, we estimate the probability of a given worker being selected into employment by the $\mathrm{COO}$, while controlling for farm level variables that affect the probability of being hired independently of the incentive scheme in place. These farm level variables measure the supply and demand of labor.

We measure labor supply using personnel records on the number of workers available for hire on the farm on any given day. We measure the demand for labor using the total daily fruit yield on each site on the farm. The total yield is orthogonal to the incentive scheme as it is determined by planting decisions taken one or two years earlier. Fields are located on two sites, of which we use the largest for the analysis as fruit in the smaller site begins to ripen only after the introduction of the performance bonus scheme. Since both sites hire workers from the same pool, we control for yields in each site separately.

We then estimate the following conditional logit model, where observations are grouped by worker,

$$
\operatorname{Pr}\left(p_{i t}=1\right)=\Lambda\left(B_{t}, B_{t} \times C_{i}, X_{t}^{D}, X_{t}^{S}, X_{i t}\right) .
$$

$p_{i t}=1$ if worker $i$ is selected by the COO to pick on day $t$ on the main site, and 0 if they are assigned to non-picking tasks. $B_{t}$ is the performance bonus dummy, $C_{i}$ is a dummy variable equal to one if worker $i$ is socially connected to any of the managers along any dimension of nationality, arrival cohort, and living site, and is zero otherwise. $X_{t}^{D}$ and $X_{t}^{S}$ proxy the demand and supply of labor on day $t$. To allow for a workers' previous performance to affect their probability of being selected, $X_{i t}$ measures worker $i$ 's productivity on the last day she picked, in percentage deviation from the mean productivity on that day, to remove the effects of factors that determine 
the productivity of all workers and are beyond the worker's control. ${ }^{38}$

All continuous variables are divided by their standard deviations so that one unit increase can be interpreted as an increase of one standard deviation. We report odds ratios throughout, and standard errors are calculated using the delta method.

Column 1 of Table A1 shows that, other things equal, there is no differential effect on socially connected or unconnected workers of being selected to pick fruit after the introduction of the performance bonus. The other coefficients show that, as expected, workers are more likely to be assigned to fruit picking tasks on days in which the fields on the main site bears more fruit and on days in which they face less competition from other workers.

Conditional on not being selected to pick on the main site on a given day, a worker can either be assigned to other tasks on the main site, to work on the other site, or be left unemployed for the day. The next specification checks whether the assignment of workers to non picking tasks varies differentially by socially connected and unconnected workers, when the performance bonus is introduced. The result in Column 2 again shows there to be no such differential effect of the COO's decision across workers based on their social connection to managers. The pattern of other coefficients confirms that the introduction of the bonus scheme significantly raises the probability of being unemployed. As expected, the probability of being unemployed for the day is lower when yields are higher and when the stock of available workers is lower.

\section{References}

[1] Akerlof.G.A (1982) "Labor Contracts as a Partial Gift Exchange", Quarterly Journal of Economics 97: 543-69.

[2] AKerlof.G.A AND J.L.Yellen (1988) "Fairness and Unemployment", American Economic Review Papers and Proceedings 78: 44-9.

[3] BAndiera.o, i.BARAnkay, And i.RASul (2005a) "Social Preferences and the Response to Incentives: Evidence From Personnel Data", Quarterly Journal of Economics 120: 917-62.

[4] BANDIERA.O, I.BARANKAY, AND I.RASUl (2005b) "Incentives for Managers and Inequality Among Workers: Evidence from a Firm Level Experiment", forthcoming Quarterly Journal of Economics.

[5] BARnard.C (1938) The Functions of the Executive, Cambridge: Harvard University Press.

\footnotetext{
${ }^{38}$ We first take the deviation of the worker's productivity from the field average productivity on each field he picked on the day he was last selected to pick, and then calculate a weighted average of this across all fields he worked on where the weights are based on the number of pickers on the field.
} 
[6] Bertrand.m And A.schoar (2003) "Managing With Style: The Effect of Managers on Firm Policies", Quarterly Journal of Economics 118: 1169-208.

[7] Bertrand.M, F.Kramarz, A.schoar, And D.Thesmar (2005) Politically Connected CEOs and Corporate Outcomes: Evidence from France, mimeo, University of Chicago.

[8] BeWley.t.F (1999) Why Wages Don't Fall During a Recession, Cambridge: Harvard University Press.

[9] Charness.G And P.Kuhn (2005) Pay Inequality, Pay Secrecy, and Effort: Theory and Evidence, mimeo, University of California, Santa Barbara.

[10] FeHr.E AND U.Fischbacher (2002) "Why Social Preferences Matter - The Impact of NonSelfish Motives on Competition, Cooperation and Incentives", Economic Journal 112: C1C33.

[11] FernANDEZ.R.M, E.J.CAStillo, AND P.MOORE (2000) "Social Capital at Work:Networks and Employment at a Phone Center", American Journal of Sociology 105: 1288-356.

[12] FREY.B.S AND F.oBerholzer-GeE (1997) "The Cost of Price Incentives: An Empirical Analysis of Motivation Crowding- Out", American Economic Review 87: 746-55.

[13] Garicano.t, I.PAlacios, And C.Prendergast (2005) "Favoritism under Social Pressure", Review of Economics and Statistics 87: 208-16.

[14] Giuliano.t, D.t.levine, And J.Leonard (2005) Do Race, Gender, and Age Differences Affect Manager-Employee Relations? An Analysis of Quits, Dismissals, and Promotions at a Large Retail Firm, mimeo, University of California Berkeley.

[15] HARRISON.G AND J.LIST (2004) "Field Experiments", Journal of Economic Literature 152: 1009-55.

[16] Holmstrom.B And P.milgrom (1991) "Multitask Principal-Agent Analyses: Incentive Contracts, Asset Ownership, and Job Design", Journal of Law, Economics and Organization 7: $24-52$.

[17] ICHNIOWSKI.C AND K.L.SHAW (2003) "Beyond Incentive Pay: Insiders' Estimates of the Value of Complementary Human Resource Management Practices", Journal of Economic Perspectives 17: 155-78.

[18] ICHNiOWSki.C AND K.L.SHAW (2005) Connective Capital: Building Problem-Solving Networks Within Firms, mimeo, Stanford University. 
[19] KAndel.E AND E.LAzEAR (1992) "Peer Pressure and Partnerships", Journal of Political Economy 100: 801-13.

[20] Kofman.f And J.LAwarree (1993) "Collusion in Hierarchical Agency", Econometrica 61: 629-56.

[21] KRAmarz.F And D.Thesmar (2005) Social Networks in the Boardroom, CEPR Discussion Paper No. 5496.

[22] KREPS.D.M (1997) "The Interaction Between Norms and Economic Incentives Intrinsic Motivation and Extrinsic Incentives", American Economic Review Papers and Proceedings 87: $359-64$.

[23] LABAnd.D.n AND M.J.PIETTE (1994) "Favoritism versus Search for Good Papers: Empirical Evidence Regarding the Behavior of Journal Editors", Journal of Political Economy 102: 194-203.

[24] LAZEAR.E.P (1989) "Pay Equality and Industrial Politics", Journal of Political Economy 97: 561-80.

[25] LAZEAR.E.P (2000) "Performance Pay and Productivity", American Economic Review 90: $1346-61$.

[26] Malmendier.u AND G.TATE (2005) "CEO Overconfidence and Corporate Investment", Journal of Finance 60: 2661-700.

[27] MaYo.e (1933) The Human Problems of an Industrial Civilization, New York: Macmillan.

[28] mian.A.R And A.I.Khwaja (2005) "Do Lenders Favor Politically Connected Firms? Rent Provision in an Emerging Financial Market", Quarterly Journal of Economics 120: 1371-1411.

[29] Milgrom.P.R (1988) "Employment Contracts, Influence Activities, and Efficient Organization Design", Journal of Political Economy 96: 42-60.

[30] Milgrom.P.R AND J.Roberts (1990) "The Efficiency of Equity in Organizational Decision Processes", American Economic Review Papers and Proceedings 80: 154-9.

[31] NAGin.D, J.B.REBitzer, S.SAnders, And L.J.TAylor (2002) "Monitoring, Motivation, and Management: The Determinants of Opportunistic Behavior in a Field Experiment", American Economic Review 92: 850-73. 
[32] PAARSCH.H.J AND B.ShEARER (1999) "The Response of Worker Effort to Piece Rates: Evidence from the British Columbia Tree-Planting Industry", Journal of Human Resources 643-67.

[33] Podolny.J.m And J.n.Baron (1997) "Resources and Relationships: Social Networks and Mobility in the Workplace", American Sociological Review 62: 673-93.

[34] PRendergast.C AND R.H.topel (1996) "Favoritism in Organizations", Journal of Political Economy 104: 958-78.

[35] Roethlisberger.f.J And W.DiCkson (1939) Management and the Worker, Cambridge: Harvard University Press.

[36] Rotemberg.J.J (1994) "Human Relations in the Workplace", Journal of Political Economy 102: 684-717.

[37] ROY.D (1952) "Quota Restriction and Goldbricking in a Machine Shop", American Journal of Sociology 57: 427-42.

[38] TIROLE.J (1986) "Hierarchies and Bureaucracies: On the Role of Collusion in Organizations", Journal of Law, Economics and Organizations 2: 181-214.

[39] Tirole.J And R.Benabou (2003) "Intrinsic and Extrinsic Motivation", Review of Economic Studies 70: 489-520.

[40] Thomas.D.A (1990) "The Impact of Race on Managers' Experiences of Developmental Relationships", Journal of Organizational Behavior 11: 479-92.

[41] TSUI.A.S AND C.A.oreILly (1989) "Beyond Simple Demographic Effects: The Importance of Relational Demography in Superior-Subordinate Dyads", Academy of Management Journal 32: $402-23$.

[42] Wesolowski.m.A And K.W.mossholder (1997) "Relational Demography in SupervisorSubordinate Dyads: Impact on Subordinate Job Satisfaction, Burnout, and Perceived Procedural Justice", Journal of Organizational Behavior 18: 351-62. 
Figure 1: The Allocation of Managerial Effort and Average Productivity

(Only low ability worker is socially connected to manager)

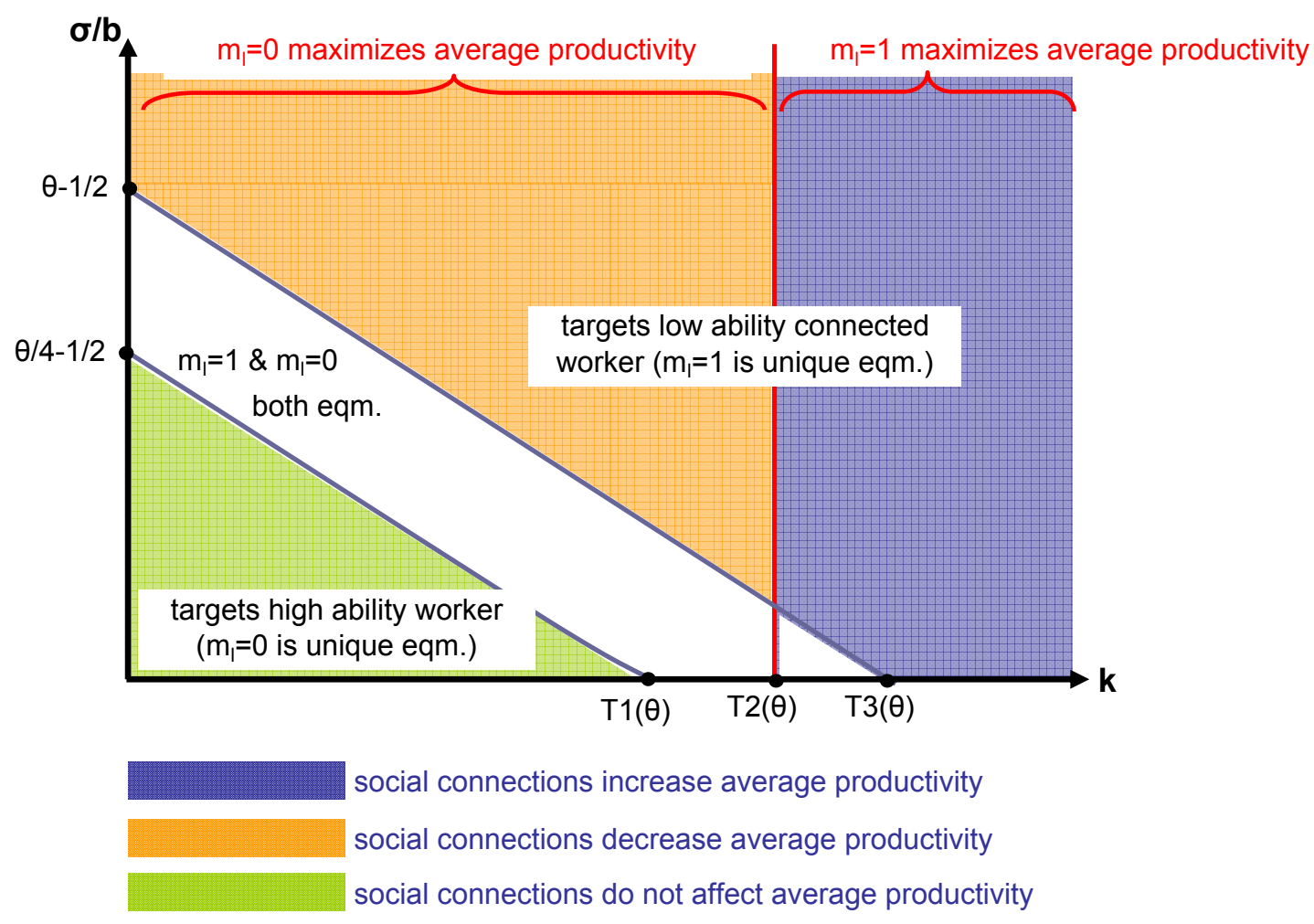

\section{Notation}

$\theta=$ cost of effort ratio (worker l/worker h)

$\mathrm{k}=$ strength of complementarity

$\sigma=$ strength of social preferences

$b=$ strength of managerial incentives 


\section{Figure 2a: Worker Productivity by Connectivity Managers Paid Fixed Wages}

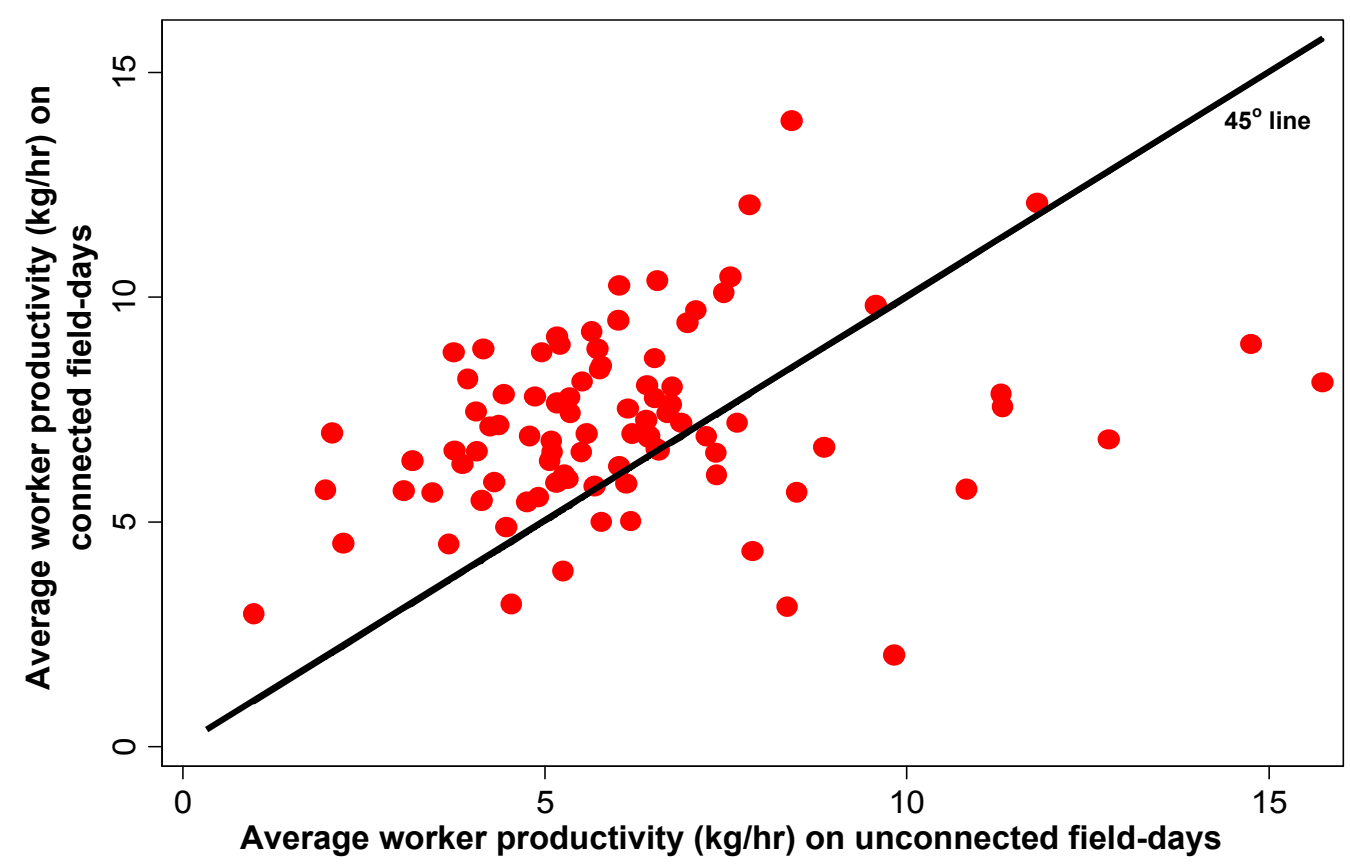

Figure 2b: Worker Productivity by Connectivity Managers Paid Performance Bonus

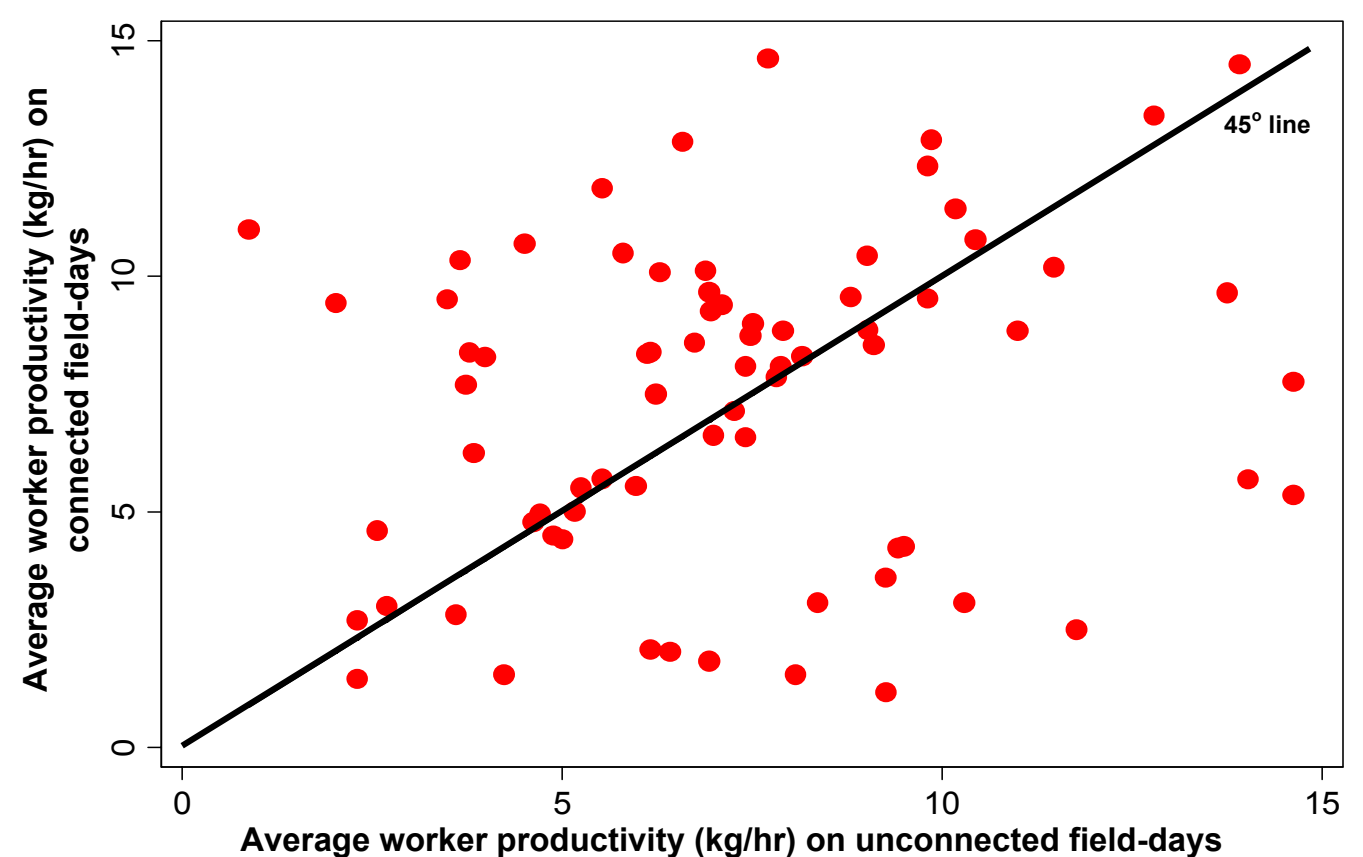

Notes: A manager and given worker $i$ are defined to be connected if they are either of the same nationality, live in the same area, or are in the same arrival cohort. In each figure we plot the average productivity of a worker on field-days in which she is not socially connected to any of her managers, against her average productivity on field-days in which she is socially connected to at least one of her managers. These figures cover the subset of workers whom we observe being connected and unconnected on different field-days within the same managerial incentive scheme. In Figure $2 a$, which is based on field-days in which managers are paid a fixed wage, there are 92 such workers. In Figure $2 b$, which is based on field-days on which managers are paid a performance bonus, there are 74 such workers. 
Table 1: Descriptives on the Social Connectivity Between Workers and Managers, by Managerial Incentive Scheme (Worker-Field-Day Level)

All observations are at the worker-field-day level

Means, standard deviation between workers in parentheses, and standard deviation within worker in brackets

\section{Managerial Incentive Scheme}

Fixed Wages $\quad$ Performance Bonus

Share of managers connected to $i\left(C_{i f t}\right)$

.433

Share of managers who are the same nationality as $i$

Share of managers who are in the same living area as $i$

Share of managers who are from the same arrival cohort as $i$

Notes: All variables are defined at the worker-field-day level. A manager and worker are defined to be resident in the same living area if they live within five caravans from each other on the farm. A manager and worker are defined to be in the same arrival cohort if they have identification numbers within the same ten digit window. A manager and given worker $i$ are defined to be connected if they are either of the same nationality, live in the same area, or are in the same arrival cohort. Each statistic is based on those workers that are connected to at least one manager along at least one of the three dimensions. There are 267 such workers when managers are paid fixed wages, and 212 such connected workers when managers are paid a performance bonus. On average, each worker is observed picking on 21 field-days when managers are paid fixed wages, and 29 field-days when managers are paid a performance bonus. Overall there are 7818 worker-field-day observations when managers are paid fixed wages, and 4469 worker-field-day observations when managers are paid a performance bonus. 
Table 2: Worker Productivity (kg/hr), by Social Connectivity to Managers and Managerial Incentive Scheme

All observations are at the worker-field-day level

Means, standard errors in parentheses

Managerial Incentive Scheme

Fixed Wages Performance Bonus Difference

\begin{tabular}{|c|c|c|c|}
\hline Unconnected on field-day $\left(\mathrm{DC}_{\mathrm{ift}}=0\right)$ & $\begin{array}{l}6.95 \\
(.173)\end{array}$ & $\begin{array}{l}9.11 \\
(.568)\end{array}$ & $\begin{array}{l}2.15^{\star * \star} \\
(.530)\end{array}$ \\
\hline Connected on field-day $\left(D C_{i f t}=1\right)$ & $\begin{array}{c}8.27 \\
(.244)\end{array}$ & $\begin{array}{l}9.23 \\
(.476)\end{array}$ & $\begin{array}{l}.962^{* * *} \\
(.324)\end{array}$ \\
\hline Difference & $\begin{array}{l}1.31^{* * *} \\
(.257)\end{array}$ & $\begin{array}{l}.123 \\
(.702)\end{array}$ & $\begin{array}{l}1.20 * * \\
(.616)\end{array}$ \\
\hline
\end{tabular}

Notes: ${ }^{* * *}$ denotes significance at $1 \%,{ }^{* *}$ at $5 \%$, and ${ }^{*}$ at $10 \%$. All variables are defined at the worker-field-day level. The standard errors are clustered at the worker level. Productivity is measured as the number of kilograms of fruit picked per hour by the worker on the field-day. A manager and given worker $i$ are defined to be connected if they are either of the same nationality, live in the same area, or are in the same arrival cohort. A worker is defined to be unconnected on the field-day if she is not socially connected to any of her managers that field-day. A worker is defined to be connected on the field-day if she is socially connected to at least one of her managers. The standard errors on the differences, and difference-in-difference, are estimated from running the corresponding least squares regression, allowing the standard errors to be clustered by worker. 
Table 3: Social Connections and Managerial Incentives

Dependent Variable $=$ Log of worker's productivity (kilograms picked per hour on the field-day)

Standard errors reported in parentheses, allowing for clustering at worker level (Columns 1 to 4 ), clustering at the field-date level in Column 5

\begin{tabular}{|c|c|c|c|c|c|}
\hline & $\begin{array}{l}\text { (1) Any Managers } \\
\text { Connected To }\end{array}$ & $\begin{array}{l}\text { (2) Share of Managers } \\
\text { Connected To }\end{array}$ & $\begin{array}{l}\text { (3) Type of Social } \\
\text { Connection }\end{array}$ & $\begin{array}{l}\text { (4) Heterogeneous Effects } \\
\text { of the Bonus on Workers }\end{array}$ & $\begin{array}{l}\text { (5) Field-Date Fixed } \\
\text { Effects }\end{array}$ \\
\hline Any managers connected to $i$, fixed wages for managers $\left(\mathrm{DC}_{\text {ift }}\right)$ & $\begin{array}{l}.041^{\star *} \\
(.017)\end{array}$ & & & & \\
\hline Any managers connected to $i$, performance bonus for managers $\left(\mathrm{DC}_{\text {ift }}\right)$ & $\begin{array}{l}.003 \\
(.031)\end{array}$ & & & & \\
\hline Share of managers connected to $i$, fixed wages for managers $\left(C_{\text {ift }}\right)$ & & $\begin{array}{l}.133^{* * *} \\
(.037)\end{array}$ & & $\begin{array}{l}.123^{\star \star \star} \\
(.037)\end{array}$ & $\begin{array}{l}.099^{* *} \\
(.045)\end{array}$ \\
\hline Share of managers connected to $i$, performance bonus for managers $\left(C_{\text {ift }}\right)$ & & $\begin{array}{l}-.115 \\
(.082)\end{array}$ & & $\begin{array}{l}-.096 \\
(.082)\end{array}$ & $\begin{array}{l}-.075 \\
(.060)\end{array}$ \\
\hline Share of managers of same nationality as $i$, fixed wages for managers & & & $\begin{array}{l}.157^{\star \star \star} \\
(.047)\end{array}$ & & \\
\hline Share of managers of same nationality as $i$, performance bonus for managers & & & $\begin{array}{l}-.124 \\
(.127)\end{array}$ & & \\
\hline Share of managers living in same area as $i$, fixed wages for managers & & & $\begin{array}{l}.089^{* *} \\
(.044)\end{array}$ & & \\
\hline Share of managers living in same area as $i$, performance bonus for managers & & & $\begin{array}{l}-.076 \\
(.070)\end{array}$ & & \\
\hline Share of managers of same arrival cohort as $i$, fixed wages for managers & & & $\begin{array}{l}.189^{\star \star} \\
(.081)\end{array}$ & & \\
\hline Share of managers of same arrival cohort as $i$, performance bonus for managers & & & $\begin{array}{l}-.076 \\
(.193)\end{array}$ & & \\
\hline Difference-in-difference estimate & $\begin{array}{l}.039 \\
(.031)\end{array}$ & $\begin{array}{l}.249^{\star * \star} \\
(.086)\end{array}$ & & $\begin{array}{l}.219^{\star *} \\
(.089)\end{array}$ & $\begin{array}{l}.174^{\star *} \\
(.075)\end{array}$ \\
\hline Interactions of nationality $\mathrm{x}$ performance bonus dummy & Yes [.169] & Yes [.030] & Yes [.056] & No & No \\
\hline Interactions of living site x performance bonus dummy & Yes [.000] & Yes [.000] & Yes [.000] & No & No \\
\hline Interactions of arrival cohort x performance bonus dummy & Yes [.000] & Yes [.000] & Yes [.000] & No & No \\
\hline Interactions of worker fixed effect x performance bonus dummy & No & No & No & Yes [.000] & Yes [.000] \\
\hline Field-date fixed effects & No & No & No & No & Yes \\
\hline $\begin{array}{l}\text { Adjusted R-squared } \\
\text { Number of observations (worker-field-day) }\end{array}$ & $\begin{array}{l}.4124 \\
12287\end{array}$ & $\begin{array}{l}.4130 \\
12287\end{array}$ & $\begin{array}{l}.4135 \\
12287\end{array}$ & $\begin{array}{l}.4214 \\
12287\end{array}$ & $\begin{array}{l}.5463 \\
12287\end{array}$ \\
\hline
\end{tabular}

Notes: *** denotes significance at $1 \%$, "* at $5 \%$, and * at $10 \%$. In Columns 1 to 4 the standard errors allow for clustering at the worker level. In Column 5 standard errors are clustered at the field-date level. All specifications control for worker, field, and manager fixed effects. The other controls included in specifications 1 to 3 include the managerial performance bonus dummy, the worker's picking experience, the field life cycle, a time trend, and interactions between the performance bonus dummy and the worker's nationality, arrival cohort, and living site. The field life cycle is defined as the nth day the field is picked divided by the total number of days the field is picked over the season. In Columns 4 and 5 these interactions are replaced by interactions of the worker fixed effect and the performance bonus dummy. Column 5 also controls for a
series of field-date fixed series of field-date fixed effects and hence the field life cycle and time trend are dropped from this specification. All continuous variables are in logarithms. A manager and given worker i are defined to be connected if they are either of the same nationality, live in the same area, or are is defined to be connected on the field-day if she is socially connected to at least one of her managers. The difference-in-difference estimate is the difference in the effect of social connections on worker productivity by managerial incentive scheme. At the foot of each column we report the p-value on the F-test on the joint significance the interaction terms with the performance bonus dummy. 


\section{Table 4: Robustness of Results to Time Effects}

Dependent Variable $=$ Log of worker's productivity (kilograms picked per hour on the field-day)

Standard errors reported in parentheses, allowing for clustering at worker level

\begin{tabular}{|c|c|c|c|c|}
\hline & $\begin{array}{l}\text { (1) Farm Level } \\
\text { Time Trend }\end{array}$ & $\begin{array}{l}\text { (2) Field Specific } \\
\text { Time Trend }\end{array}$ & $\begin{array}{c}\text { (3) Worker Specific } \\
\text { Time Trend }\end{array}$ & $\begin{array}{l}\text { (4) Placebo } \\
\text { Bonus Based on } \\
\text { Field Life Cycle }\end{array}$ \\
\hline Share of managers connected to $i$, fixed wages for managers & $.152^{* * *}$ & $.182^{* * *}$ & $.173^{* *}$ & \\
\hline Share of managers connected to $i$, performance bonus for managers & $\begin{array}{l}(.040) \\
-.071 \\
(.086)\end{array}$ & $\begin{array}{l}.008) \\
-.087 \\
(.113)\end{array}$ & $\begin{array}{l}(.001) \\
.435 \\
(.399)\end{array}$ & \\
\hline Share of managers connected to $i$, fixed wages for managers $x 2$ nd quarter dummy (31st May) & $\begin{array}{l}-.040 \\
(.061)\end{array}$ & & & \\
\hline Share of managers connected to $i$, performance bonus for managers $x$ 4th quarter dummy (29th July) & $\begin{array}{l}-.116 \\
(.099)\end{array}$ & & & \\
\hline Share of managers connected to $i$, fixed wages for managers $\mathrm{x}$ field life cycle & & $\begin{array}{l}-.134 \\
(.120)\end{array}$ & & \\
\hline Share of managers connected to $i$, performance bonus for managers $\mathrm{x}$ field life cycle & & $\begin{array}{c}-.117 \\
(.195)\end{array}$ & & \\
\hline Share of managers connected to $i$, fixed wages for managers $x$ days on farm for worker $i$ & & & $\begin{array}{c}-.017 \\
(.031)\end{array}$ & \\
\hline Share of managers connected to $i$, performance bonus for managers $x$ days on farm for worker $i$ & & & $\begin{array}{c}-.141 \\
(.105)\end{array}$ & \\
\hline Share of managers connected to $i$, placebo bonus based on field life cycle $=0$ & & & & $\begin{array}{c}-.087 \\
(.088)\end{array}$ \\
\hline Share of managers connected to $i$, placebo bonus based on field life cycle $=1$ & & & & $\begin{array}{l}-.033 \\
(.149)\end{array}$ \\
\hline Interactions of nationality $\mathrm{x}$ performance bonus dummy & Yes & Yes & Yes & Yes \\
\hline Interactions of living site x performance bonus dummy & Yes & Yes & Yes & Yes \\
\hline Interactions of arrival cohort $x$ performance bonus dummy & Yes & Yes & Yes & Yes \\
\hline Adjusted R-squared & .4142 & .4269 & .4142 & .5618 \\
\hline Number of observations (worker-field-day) & 12287 & 12287 & 12287 & 1584 \\
\hline
\end{tabular}

Notes: *** denotes significance at $1 \%$, ** at $5 \%$, and * at $10 \%$. Standard errors allow for clustering at the worker level. All specifications control for worker, field, and manager fixed effects. The other controls included in each specification include the managerial performance bonus dummy, the worker's picking experience, the field life cycle, and a time trend. The field life cycle is defined as the nth day the field is picked divided by the total number of days the field is picked over the season. All continuous variables are in logarithms. A manager and given worker $i$ are defined to be connected if they are either of the same nationality, live in the same area, or are in the same arrival cohort. The samples in Columns 1 to 3 are restricted to workers that are connected to at leas one manager on at least one field-day. In Column 1 the 2 nd quarter dummy is defined to be equal to zero before May 31 st and one thereatter. The 4th quarter dummy is defined to be equal to zero before July 29 th and one thereafter. These dummy variables cycle is defined to be zero if the field is less than 53 of the way though its life cycle, and one otherwise In this column the sample is restricted to fields that are only operated in the period when managers are paid a performance bonus (after June 27 th). The interaction terms at the foot of the table are defined with respect to the placebo bonus dummy variable in Column 4 . The difference-in-difference estimate is the difference in the effect of social connections on worker productivity by managerial incentive scheme. 
Table 5: Robustness of Results to Using Alternative Samples of Workers

Dependent Variable $=$ Log of worker's productivity (kilograms picked per hour on the field-day)

Standard errors reported in parentheses, allowing for clustering at worker level

(1) Available for Picking Three Weeks Either Side of the Change in Managerial Incentives
(2) Pick Under Both Managerial (3) Pick At Least Six Days Incentive Schemes
Incentive Schemes

\begin{tabular}{|c|c|c|c|}
\hline $\begin{array}{l}\text { Share of managers connected to } i \text {, fixed wages for managers } \\
\text { Share of managers connected to } i \text {, performance bonus for managers }\end{array}$ & $\begin{array}{l}.145^{\star * *} \\
(.043) \\
-.053 \\
(.114)\end{array}$ & $\begin{array}{l}.130^{* * *} \\
(.039) \\
-.108 \\
(.083)\end{array}$ & $\begin{array}{l}.158^{* * *} \\
(.041) \\
-.083 \\
(.088)\end{array}$ \\
\hline Difference-in-difference estimate & $\begin{array}{c}.198^{*} \\
(.118)\end{array}$ & $\begin{array}{l}.238^{* * *} \\
(.088)\end{array}$ & $\begin{array}{l}.241^{* * *} \\
(.096)\end{array}$ \\
\hline $\begin{array}{l}\text { Interactions of nationality } x \text { performance bonus dummy } \\
\text { Interactions of living site } x \text { performance bonus dummy } \\
\text { Interactions of arrival cohort x performance bonus dummy }\end{array}$ & $\begin{array}{l}\text { Yes } \\
\text { Yes } \\
\text { Yes }\end{array}$ & $\begin{array}{l}\text { Yes } \\
\text { Yes } \\
\text { Yes }\end{array}$ & $\begin{array}{l}\text { Yes } \\
\text { Yes } \\
\text { Yes }\end{array}$ \\
\hline $\begin{array}{l}\text { Adjusted R-squared } \\
\text { Number of observations (worker-field-day) }\end{array}$ & $\begin{array}{l}.4219 \\
8069\end{array}$ & $\begin{array}{l}.4303 \\
10542\end{array}$ & $\begin{array}{l}.4278 \\
8884\end{array}$ \\
\hline
\end{tabular}

Notes: ${ }^{* *}$ denotes significance at $1 \%,{ }^{* *}$ at $5 \%$, and ${ }^{*}$ at $10 \%$. Standard errors allow for clustering at the worker level. All specifications control for worker, field, and manager fixed effects. The other controls included in each specification include the managerial performance bonus dummy, the worker's picking experience, the field life cycle, and a time trend. The field life cycle is defined as the nth day the field is picked divided by the total number of days the field is picked over the season. All continuous variables are in logarithms. A manager and given worker $i$ are defined to be connected if they are either of the same nationality, live in the same area, or are in the same arrival cohort. The samples are all restricted to workers that are connected to at least one manager on at least one field-day. The sample in Column 1 is further restricted to workers that are physically present on the farm three weeks wither side of the change in managerial incentives (June 27th). The sample in Column 2 is further restricted to workers that are observed picking fruit on at least one day under both managerial incentive schemes. The sample in Column 3 is further restricted to workers that are observed picking for at least six days under both managerial incentive schemes. The difference-in-difference estimate is the difference in the effect of social connections on worker productivity by managerial incentive
scheme. 


\section{Table 6: Rival Favors}

Dependent Variable $=$ Log of worker's productivity (kilograms picked per hour on the field-day) Standard errors reported in parentheses, allowing for clustering at worker level

\section{Any Managers Connected To Share of Managers Connected To}

\begin{tabular}{|c|c|c|c|c|}
\hline & (1) & (2) & (3) & (4) \\
\hline $\begin{array}{l}\text { Any managers connected to } i \text {, fixed wages for managers } \\
\text { Any managers connected to } i \text {, fixed wages for managers } \\
x \text { share of workers on the field that are socially connected to } \\
\text { Share of managers connected to } i \text {, fixed wages for managers } \\
x \text { average social connectivity of workers on the field-date to }\end{array}$ & $\begin{array}{l}.041^{* *} \\
(.017)\end{array}$ & $\begin{array}{l}.191^{\star * *} \\
(.044) \\
-.261^{* \star *} \\
(.075)\end{array}$ & $\begin{array}{l}.133^{* * *} \\
(.037)\end{array}$ & $\begin{array}{l}-.551^{* *} \\
(.252)\end{array}$ \\
\hline $\begin{array}{l}\text { Any managers connected to } i \text {, performance bonus for managers } \\
\text { Any managers connected to } i \text {, performance bonus for managers } \\
x \text { share of workers on the field that are socially connected to } \\
\text { Share of managers connected to } i \text {, performance bonus for managers } \\
x \text { average social connectivity of workers on the field-date to }\end{array}$ & $\begin{array}{l}.003 \\
(.031)\end{array}$ & $\begin{array}{l}-.168 \\
(.123) \\
.273 \\
(.215)\end{array}$ & $\begin{array}{l}-.115 \\
(.082)\end{array}$ & $\begin{array}{l}-.119 \\
(.223)\end{array}$ \\
\hline $\begin{array}{l}\text { Share of workers on the field that are socially connected to } \\
\text { managers, fixed wages for managers } \\
\text { Share of workers on the field that are socially connected to } \\
\text { managers, performance bonus for managers } \\
\text { Average social connectivity of workers on the field-date to } \\
\text { managers, fixed wages for managers } \\
\text { Average social connectivity of workers on the field-date to } \\
\text { managers, performance bonus for managers }\end{array}$ & & $\begin{array}{l}.045 \\
(.067) \\
-.045 \\
(.209)\end{array}$ & & $\begin{array}{l}.059 \\
(.133) \\
-.268 \\
(.324)\end{array}$ \\
\hline $\begin{array}{l}\text { Interactions of nationality x performance bonus dummy } \\
\text { Interactions of living site x performance bonus dummy } \\
\text { Interactions of arrival cohort x performance bonus dummy }\end{array}$ & $\begin{array}{l}\text { Yes } \\
\text { Yes } \\
\text { Yes }\end{array}$ & $\begin{array}{l}\text { Yes } \\
\text { Yes } \\
\text { Yes }\end{array}$ & $\begin{array}{l}\text { Yes } \\
\text { Yes } \\
\text { Yes }\end{array}$ & $\begin{array}{l}\text { Yes } \\
\text { Yes } \\
\text { Yes }\end{array}$ \\
\hline $\begin{array}{l}\text { Adjusted R-squared } \\
\text { Number of observations (worker-field-day) }\end{array}$ & $\begin{array}{l}.4124 \\
12287\end{array}$ & $\begin{array}{l}.4131 \\
12287\end{array}$ & $\begin{array}{l}.4130 \\
12287\end{array}$ & $\begin{array}{l}.4131 \\
12287\end{array}$ \\
\hline
\end{tabular}

Notes: ${ }^{* \star}$ denotes significance at $1 \%,{ }^{* *}$ at $5 \%$, and ${ }^{*}$ at $10 \%$. Standard errors allow for clustering at the worker level. All specifications control for worker, field, and manager fixed effects. The other controls included in each specification include the managerial performance bonus dummy, the worker's picking experience, the field life cycle, and a time trend. The field life cycle is defined as the nth day the field is picked divided by the total number of days the field is picked over the season. All continuous variables are in logarithms. A manager and given worker $i$ are defined to be connected if they are either of the same nationality, live in the same area, or are in the same arrival cohort. In Columns 1 to 4 the sample is restricted to workers that are connected to at least one connected on the field-day if she is socially connected to at least one of her managers. 
Table A1: Social Connections, Selection, and Managerial Incentives

Conditional logit estimates

Column 1: Dependent Variable $=1$ if worker $i$ is chosen to pick on day $t$ in main site, 0 if worker is assigned to non-picking tasks

Column 2: Dependent Variable $=1$ if worker $i$ is unemployed on day $t, 0$ if assigned to non-picking tasks

Odd ratios reported, standard errors in parentheses, clustered by worker

\section{Probability of Being \\ Selected to Pick}

\section{Probability of Being}

Unemployed

Performance bonus for managers

1.34

$(.495)$

$2.04^{*}$

$(.764)$

Performance bonus for managers $x$ worker $i$ is socially connected

.524

.605

$(.214)$

$2.24^{* * *}$

$(.153)$

$.883^{* * *}$

$(.036)$

.380 ***

$(.037)$

$1.16^{*}$

$(.091)$

(.253)

$.802^{* * *}$

$(.057)$

$.800^{* * *}$

$(.032)$

$1.83^{* * *}$

(.178)

Worker $i$ 's previous deviation from mean productivity

Log-likelihood

$-5186.8$

1.07

(.107)

Number of observations (worker-day)

15551

$-3208.5$

9808

Notes: ${ }^{* * *}$ denotes that the log odds ratio is significantly different from one at $1 \%,{ }^{* *}$ at $5 \%$, and ${ }^{*}$ at $10 \%$ levels. Conditional logit estimates are reported where observations are grouped by worker. All continuous variables are divided by their standard deviations so that one unit increase can be interpreted as increase by one standard deviation. A manager and given worker i are defined to be connected if they are either of the same nationality, live in the same area, or are in the same arrival cohort. "Total yield" on the site is the total kilograms of the fruit picked on the site-day. The "number of workers available to pick fruit" is the total number of individuals that are on the farm that day and are available for fruit picking. "Worker $i$ 's previous deviation from mean productivity" is defined on the last day the worker was selected to pick. We first take the deviation of the worker's productivity from the field average productivity on each field he picked on the day he was last selected to pick, and then calculate a weighted average of this across all fields he worked on where the weights are based on the number of pickers on the field. Worker $i$ is defined to be unemployed on day $t$ if she is present on the farm but is not assigned to any paid tasks. 


\section{Table A2: Allocation of Workers and Managers}

Dependent Variable $=\log (1+$ share of managers that are connected to worker $i$ on field $f$ day $t)$

Each cell reports the $p$-value of the test of the hypothesis that the coefficient on the interaction term is zero

\begin{tabular}{|c|c|c|c|c|c|c|c|}
\hline & (1) & $(2)$ & (3) & (4) & (5) & (6) & $(7)$ \\
\hline Performance bonus for managers $\mathrm{x}$ field life cycle & .935 & .414 & .296 & .653 & .509 & .771 & .845 \\
\hline Performance bonus for managers $\mathrm{x}$ trend & & .219 & .305 & .293 & .274 & .231 & .239 \\
\hline Performance bonus for managers $\mathrm{x}$ worker's experience & & & .192 & .192 & .184 & .186 & .186 \\
\hline Performance bonus for managers $\mathrm{x}$ number of workers & & & & .527 & .587 & .572 & .557 \\
\hline Performance bonus for managers $\mathrm{x}$ number of managers & & & & & .889 & .975 & .879 \\
\hline Performance bonus for managers $\mathrm{x}$ total hours worked & & & & & & .185 & .364 \\
\hline Performance bonus for managers $\mathrm{x}$ total kilos of fruit picked & & & & & & & .952 \\
\hline F-test of joint significance of all interaction terms & & .346 & .334 & .617 & .684 & .665 & .795 \\
\hline
\end{tabular}

Notes: A manager and given worker $i$ are defined to be connected if they are either of the same nationality, live in the same area, or are in the same arrival cohort. Standard errors allow for clustering at the worker level. All specifications control for worker, field, and manager fixed effects. The other controls included in each specification include the managerial performance bonus dummy, the worker's picking experience, the field life cycle, and a time trend. The field life cycle is defined as the nth day the field is picked divided by the total number of days the field is picked over the season. The number of workers, number of supervisors, total kilos picked and total hours worked are defined at the field-day level. All continuous variables are in logarithms. The null hypothesis for the F-test is that the coefficients of all the interactions are equal to zero. There are 12287 worker-field-day level observations in each regression. 


\section{Table A3: Continuous Measures of Social Connections and Managerial Incentives}

Dependent Variable = Log of worker's productivity (kilogram picked per hour on the field-day) Standard errors reported in parentheses, allowing for clustering at worker level

\begin{tabular}{|c|c|c|c|}
\hline & Nationality & Living Area & Arrival Cohort \\
\hline $\begin{array}{l}\text { Share of managers of same nationality as } i \text {, fixed wages for managers } \\
\text { Share of managers of same nationality as } i \text {, performance bonus for managers } \\
\text { Share of managers living in same area as } i \text {, fixed wages for managers } \\
\text { Share of managers living in same area as } i \text {, performance bonus for managers } \\
\text { Share of managers of same arrival cohort as } i \text {, fixed wages for managers } \\
\text { Share of managers of same arrival cohort as } i \text {, performance bonus for managers }\end{array}$ & $\begin{array}{l}.158^{* * *} \\
(.047) \\
-.074 \\
(.128)\end{array}$ & $\begin{array}{l}.097^{* *} \\
(.044) \\
-.052 \\
(.077)\end{array}$ & $\begin{array}{l}.169^{*} \\
(.097) \\
-.240^{*} \\
(.133)\end{array}$ \\
\hline Difference-in-difference estimate & $\begin{array}{l}.231^{*} \\
(.140)\end{array}$ & $\begin{array}{r}.149^{*} \\
(.078)\end{array}$ & $\begin{array}{l}.409^{* *} \\
(.170)\end{array}$ \\
\hline $\begin{array}{l}\text { Interactions of nationality } x \text { performance bonus dummy } \\
\text { Interactions of living area } x \text { performance bonus dummy } \\
\text { Interactions of arrival cohort x performance bonus dummy }\end{array}$ & $\begin{array}{l}\text { Yes }[.089] \\
\text { No } \\
\text { No }\end{array}$ & $\begin{array}{l}\text { No } \\
\text { Yes }[.000] \\
\text { No }\end{array}$ & $\begin{array}{c}\text { No } \\
\text { No } \\
\text { Yes }[.000]\end{array}$ \\
\hline $\begin{array}{l}\text { Adjusted R-squared } \\
\text { Number of observations (worker-field-day) }\end{array}$ & $\begin{array}{l}.4291 \\
8238\end{array}$ & $\begin{array}{l}.3722 \\
8262\end{array}$ & $\begin{array}{l}.4914 \\
3980\end{array}$ \\
\hline
\end{tabular}

Notes: ${ }^{* *}$ denotes significance at $1 \%,{ }^{* *}$ at $5 \%$, and ${ }^{*}$ at $10 \%$. Standard errors allow for clustering at the worker level. All specifications control for worker, field, and manager fixed effects. The other controls included in each specification include the managerial performance bonus dummy, the worker's picking experience, the field life cycle, and a time trend. The field life cycle is defined as the nth day the field is picked divided by the total number of days the field is picked over the season. All continuous variables are in logarithms. A manager and given worker $i$ are defined to be connected if they are either of the same nationality, live in the same area, or are in the same arrival cohort. In Column 1 the sample is restricted to workers that are sometimes connected to at least one manager on a field-day by nationality. In Column 2 the sample is restricted to workers that are sometimes connected to at least one manager on a field-day by living area. In Column 3 the sample is restricted to workers that are sometimes connected to at least the sample is resticl to workers that are som at difference estimate is the difference in the effect of social connections on worker productivity by managerial incentive scheme. 


\section{Table A4: Spurious Measures of Social Connections and Managerial Incentives}

Dependent Variable $=$ Log of worker's productivity (kilogram picked per hour on the field-day)

Standard errors reported in parentheses, allowing for clustering at worker level

First Name Initial Day of Month of Birth Day of Week of Birth

Share of managers that have same first name initial as $i$, fixed wages for managers

Share of managers that have same first name initial as $i$, performance bonus for managers

Share of managers that were born on the same day of the month as $i$, fixed wages for managers

Share of managers that were born on the same day of the month as $i$, performance bonus for managers

Share of managers that were born on the same day of the week as $i$, fixed wages for managers

Share of managers that were born on the same day of the week as $i$, performance bonus for managers

$-.093$

(.108)

\begin{tabular}{|c|c|c|c|}
\hline & & & $(.302)$ \\
\hline Difference-in-difference estimate & $\begin{array}{c}.083 \\
(.129)\end{array}$ & $\begin{array}{l}-.058 \\
(.140)\end{array}$ & $\begin{array}{c}.221 \\
(.203)\end{array}$ \\
\hline Interactions of first name initial x performance bonus dummy & Yes & No & No \\
\hline Interactions of day of month of birth $\mathrm{x}$ performance bonus dummy & No & Yes & No \\
\hline Interactions of day of week of birth x performance bonus dummy & No & No & Yes \\
\hline Adjusted R-squared & .4563 & .4249 & .4524 \\
\hline Number of observations (worker-field-day) & 5546 & 2274 & 2412 \\
\hline
\end{tabular}

Notes: *** denotes significance at $1 \%$, ** at $5 \%$, and * at $10 \%$. Standard errors allow for clustering at the worker level. All specifications control for worker, field, and manager fixed effects. The other controls included in each specification include the managerial performance bonus dummy, the worker's picking experience, the field life cycle, and a time trend. The field life cycle is defined as the nth day the field is picked divided by the total number of days the field is picked over the season. All continuous variables are in logarithms. A manager and given worker $i$ are defined to be connected if they are either of the same nationality, live in the same area, or are in the same arrival cohort. In Column 1 the sample is restricted to workers that are sometimes connected to at least one manager on a field-day by frst name intal (A-Z). In Column 2 he sample is resticted to workers that are solvetimes connected to al least one manager on a field-day by day of month of birth (1-31). In Column 3 the sample is restricted to workers that are 